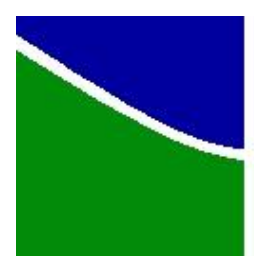

Universidade de Brasília

Departamento de Processos Psicológicos Básicos

Programa de Pós-graduação em Ciências do

Comportamento

\title{
Efeitos de mudanças sucessivas na definição de produto agregado em metacontingências
}

Fabiana Azevedo de Andrade

Fabiana Azevedo de Andrade

Brasília, Abril de 2015. 


\section{Efeitos de mudanças sucessivas na definição de produto agregado em metacontingências}

Fabiana Azevedo de Andrade

Dissertação apresentada ao Programa de Pós-Graduação em Ciências do Comportamento, Departamento de Processos Psicológicos Básicos, Instituto de Psicologia, Universidade de Brasília, como parte dos requisitos para obtenção do grau de Mestre em Ciências do Comportamento.

Orientador: Dr. João Claudio Todorov

Brasília, Abril de 2015. 
Este trabalho foi desenvolvido no Instituto de Psicologia da Universidade de Brasília com apoio da CAPES.

\section{Comissão Examinadora}

Prof. Dr. João Claudio Todorov (Presidente)

Universidade de Brasília

Prof ${ }^{\mathrm{a}}$. Dra ${ }^{\mathrm{a}}$. Raquel Aló (Membro Efetivo)

Universidade de Brasília

$\operatorname{Prof}^{a}$. Dr ${ }^{\mathrm{a}}$. Michela Ribeiro (Membro Efetivo)

Centro Universitário de Brasília

Prof $^{a}$. Dr ${ }^{\mathrm{a}}$. Raquel Maria de Melo (Membro Suplente)

Universidade de Brasília 


\section{Índice}

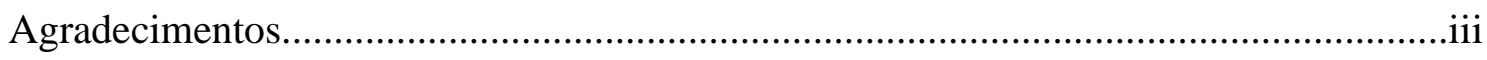

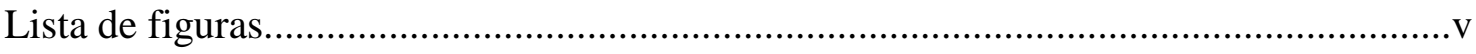

Lista de tabelas....................................................................................................

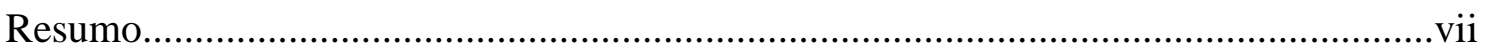

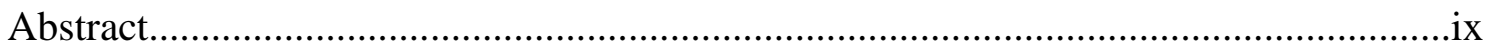

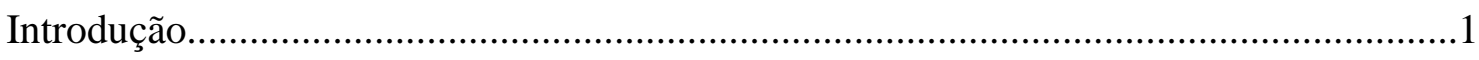

Comportamento social e metacontingência......................................................4

Estudos experimentais em metacontingência.................................................8

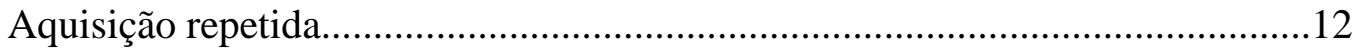

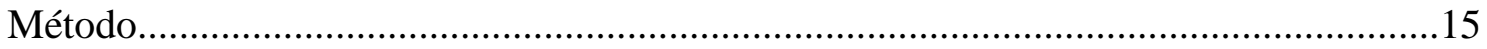

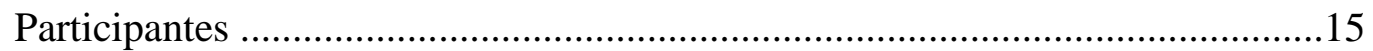

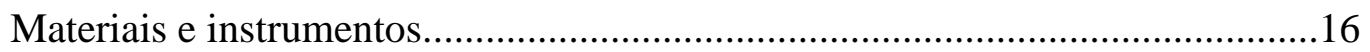

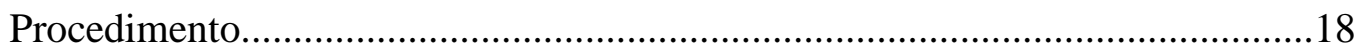

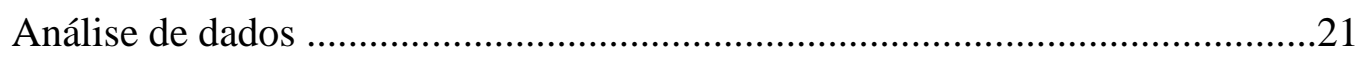

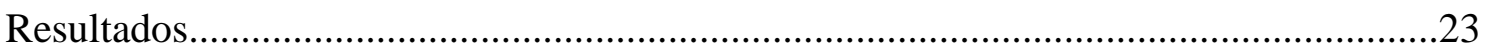

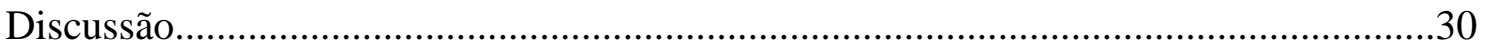

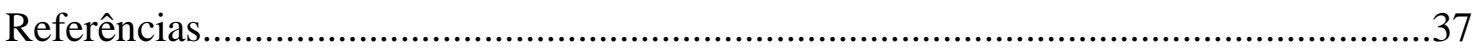

Anexo 1 - Termo de autorização para coleta de dados.................................................45

Anexo 2 - Termo de Consentimento Livre e Esclarecido..............................................46 


\section{Agradecimentos}

Mais do que o conhecimento e a experiência que adquiri nos últimos dois anos, preciso agradecer muitas coisas a muitas pessoas. A jornada foi longa, cansativa, mas muito divertida e até acolhedora, ao contrário do que "dizem por a'́". Da graduação já queria fazer o mestrado sem nem bem saber direito o que aconteceria nestes dois anos. Muitas pessoas tornaram essa jornada possível e a fizeram muito mais especial.

Primeiramente, claro, agradeço aos meus pais. Já os disse o tamanho da admiração em palavra, beijos e poemas várias vezes, mas eles merecem um lugar especial aqui também. Agradeço aos dois pelo amor e cuidado, cada qual com seu jeito, me fazem ter orgulho de quem sou. Obrigada ao meu pai pelo exemplo de aluna que deveria ser, apesar de nem sempre eu ter sido e obrigada à minha mãe que sempre vibrou tão sinceramente em cada conquista, mesmo nas mais simples. Vocês me fizeram e me fazem melhor a cada dia. À Connie também, por ser quem é, por fazer parte tão especialmente de nossa família e por todo o resto que não sei nomear, obrigada.

Aos meus irmãos, cunhada e cunhado, pelo apoio e amor. Obrigada irmão por me ajudar com os perrengues tecnológicos! Obrigada Duda, só por você existir... À toda minha família, que de longe ou de perto, me apoiaram e torceram por mim, desculpem por não ter ido nesse ou naquele evento, estava estudando! Aos meus tios e primos que entenderam que eu não poderia aceitar o convite para o almoço porque estava "atolada" com a dissertação ou por entender que eu quase chorei sem motivo algum. Aos meus padrinhos, Suzete e "Manel", que são mais do que especiais merecem o meu mais profundo agradecimento, vocês colaboraram muito para o meu gosto por ser aluna e pelas letras.

Obrigada ao Professor Todorov por dividir um pouquinho de seu vasto conhecimento comigo. Sua colaboração para minha formação começou muito antes de eu pensar em ser aluna de mestrado, lá na graduação. Obrigada por organizar o curso pelo qual sou completamente apaixonada. Agradeço por corresponder a todas as minhas expectativas (até as mais altas) e pelo aprendizado que adquiri. Obrigada pela paciência e tolerância também... Sei que muitas vezes não foi fácil...

Ao João Vianney, que pacientemente e prontamente tornou este trabalho possível com sua dedicação e disponibilidade.

Sou muito grata ao Márcio Borges Moreira, à Fernanda Mendizabal e à Lilian Rodrigues, por terem mostrado a Análise do Comportamento de um jeito mais doce e humano. À Lilian, em especial, minha gratidão pelo mundo novo que me mostrou durante o curso de extensão e os estágios supervisionados e que, com certeza, tiveram forte influência sobre minhas escolhas profissionais até aqui.

Agradeço a todos os professores do PPB pela experiência trocada e conhecimento compartilhado e a todos os funcionários do departamento, em especial à Joyce, que fez a jornada de todos que passaram por ali mais suave e ao Daniel que com tanto bom-humor, facilitou muito os dias de todos os alunos.

Meu agradecimento ao Marçal, pela amizade, carinho e permissão para coletar meus dados lá no IBAC. Obrigada à toda equipe do IBAC pelo auxílio sempre que precisei, em especial à Monique que mais do que depressa, me ajudou sempre que pôde com questões burocráticas, com tanto carinho e amizade. 
Obrigada a todos os membros da banca que tão prontamente aceitaram meu convite, disponibilizando um pouquinho de seu tempo e de seu conhecimento para este dia.

Como sou daqui, não preciso agradecer a ninguém pela acolhida, mas não posso deixar de dar meu "muito obrigada" a quem fez e faz de meus dias, os MEUS dias. Valeu a todos os coleguinhas de departamento, principalmente ao Marcelo, Rafa, Robs e Rodrigo (companheiro de correria) pela experiência trocada e pelos helps nossos de cada dia. Rafa, você merece muuuuuito mais que obrigada pela consultoria para assuntos da UnB que sempre tão prestativa, me deu.

Às minhas 7(!) queridas amigas (Ana, Bruna, Ju, Nay, Pri e Sara), eu agradeço pelos dias divididos há nove anos (!!!), sem que perdêssemos o contato e o companheirismo nos momentos marcantes de nossas vidas (Miguel, Rafa e neném), vocês estiveram presentes durante este caminho também. Sara, muito obrigada pela ajuda e pela consultoria gramatical, além claro, de toda a diversão. Meninas, valeu pela ajuda com o ensaio para a apresentação.

Obrigada a todas do "Crossroads" pela compreensão quando eu não pude participar dos encontros. Meu agradecimento especial à Deborah, que já não sei se encaixo na parte de amigos ou de família, porque já estamos juntas há tanto tempo, que já nem sei... rs...

À Débora, Lara e Marina pela amizade, companheirismo, viagens, apoio, torcida e paciência.

Ao Paulo (valeu pelas dicas também, foram valiosíssimas!), Rafa e Sara por nunca terem saído dos meus dias, até nos mais corridos por conta da UnB (Ninguém sai!).

Meu mais sincero e amoroso agradecimento ao meu querido professor Gustavo Tozzi que, mais do que "amor, casa, comida e roupa lavada" (e Nina) diariamente, me ensina como ser alguém melhor, com todo empenho e dedicação que alguém pode ter. Obrigada por além de seus dias, compartilhar comigo sua experiência acadêmica e profissional. Gu, agradeço sua paciência e cuidado, até mesmo nos momentos mais "estranhos". Obrigada por pintar o mundo de rosa pra mim. O doutorado não vem agora, mas esse mestrado já lhe deve muito!

À todos àqueles que não citei diretamente, mas que fizeram esta dissertação possível, um "MUITO OBRIGADA", do fundo do meu coração! 


\section{Lista de figuras}

Figura 1. Comparação entre contingência operante e metacontingência..........................6

Figura 2. Tabuleiro do software "Xadrez" visível aos participantes................................16

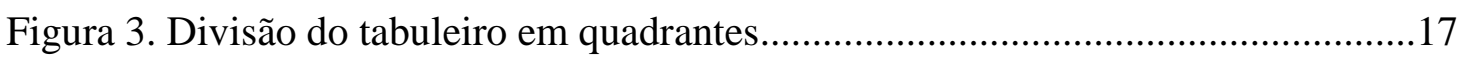

Figura 4. Output visível à pesquisadora na condição 1 .................................................17

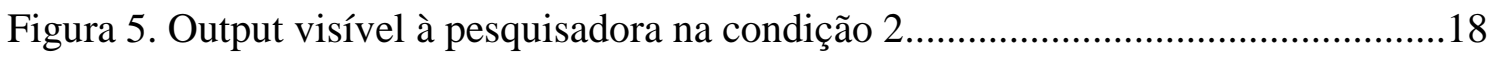

Figura 6. Dados dispostos no Output visível à pesquisadora.........................................25

Figura 7. Tela do software quando o produto agregado foi produzido...........................20

Figura 8. Disposição dos quadrantes onde os encontros foram reforçados por fase nas

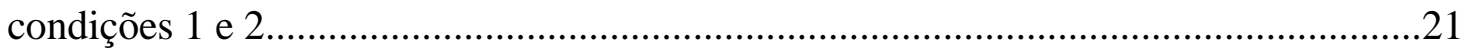

Figura 9. Curva de aprendizagem da Condição 1 em relação ao número de tentativas para a mudança de fase.

Figura 10. Curva de aprendizagem da Condição 2 em relação ao número de tentativas para a mudança de fase

Figura 11. Fases ordenadas em grau de dificuldade a partir do número médio de tentativas para as peças.

Figura 12. Fases ordenadas em grau de dificuldade de acordo com a distância total para as duplas em quadrantes necessária para a produção do PA 30

Figura 13. Fases ordenadas em grau de dificuldade a partir do número médio de tentativas para a produção do PA. 


\section{Lista de tabelas}

Tabela 1. Distância mínima em quadrantes para a produção do PA.............................24

Tabela 2. Número médio de tentativas por fase ......................................................25

Tabela 3. Tentativas emitidas pelas duplas até a mudança de fase .............................26 


\section{Resumo}

Com base nos três níveis de seleção definidos por Skinner, Sigrid Glenn criou o conceito de Metacontingência para o estudo de práticas culturais. Para investigar princípios básicos relacionados ao terceiro nível de seleção, este estudo procurou observar quais seriam os efeitos sobre a aprendizagem de duplas, a partir do número de tentativas emitidas, durante mudanças sucessivas na definição do local do produto agregado (PA). Por meio do procedimento de aquisição repetida 10 duplas participaram do experimento. $\mathrm{O}$ experimento consistiu em um jogo realizado em um tabuleiro virtual com duas peças, dividido em 16 quadrantes sem o conhecimento dos participantes. Em cada fase, o encontro entre as peças seria reforçado em um quadrante diferente, que foi previamente definido e alterado a cada fase. Foram realizadas duas condições com cinco fases cada. Cada condição consistiu em encontros promovidos pela dupla durante as cinco fases. As fases 1, 2, 3 e 4 eram iguais para as duas condições. Para a Fase 5 na Condição 1, o encontro seria reforçado no Quadrante 15 e na Condição 2, no Quadrante 11. Cada dupla participou somente de uma condição. As sete primeiras duplas participaram da Condição 1 e as três últimas da Condição 2. Comparando-se os dados da primeira e da última fase, verificou-se que o número de tentativas até a estabilidade diminuiu para as duplas 1, 2, 4 e 8 e aumentou para as duplas 3, 5, 6 e 7, 9 e 10. Para a análise de dados, foram definidos critérios de dificuldades posteriores aos experimentos para as fases e condições. De acordo com o número de tentativas emitidas pelas duplas e a quantidade mínima de quadrantes necessários para o encontro, percebeu-se que produzir o PA foi mais difícil na Fase 5 das duas condições. O experimento realizado mostrou a utilidade do procedimento e demonstrou a possibilidade de realizar pesquisa básica em metacontingência de maneira simples sem a necessidade de reforçamento adicional para o comportamento individual ou treino prévio para a tarefa. 
Palavras-chave: metacontingência; aquisição repetida; comportamento social, seleção cultural. 


\begin{abstract}
Based on three selection levels defined by Skinner, Sigrid Glenn created the concept of metacontingency for the study of cultural practices. To investigate basic principles related to the third selection level, this study searched for what would be the effects on learning during successive changes in the arrangement of the aggregate output (AO). Through repeated procurement process, 13 pairs participated in the experiment which consisted of a game performed on a virtual board with two parts, divided into 16 quadrants without the knowledge of the participants. The location of the AO was previously defined and modified at each stage. Two conditions were conducted with five phases each, differentiated only by Phase 5. Each pair took part in only one condition, the first seven participated in Condition 1 and the last three of Condition 2. Comparing the data of the first and last phase, it was found that the number of attempts to decreased stability for the pairs 1,2, 4 and 8 and increased for the pairs 3, 5, 6, 7, 9 and 10. According to the number of attempts issued by the pairs and the minimum amount of quarters required for the meeting, it was noticed that it was more difficult to produce the AO in Phase 5 of the two conditions. To data variability we cannot say systematic effects on pairs learning from the successive changes in conditions. Yet, the experiment showed the usefulness of the procedure and demonstrated the possibility of carrying out basic research metacontingency in a simple way without the need of reinforcement for individual behavior or pre-training for the task.
\end{abstract}

Keywords: metacontingency; Repeated acquisition; social behavior, cultural selection. 
Skinner escreveu sobre a evolução do comportamento humano a partir do conceito de um ambiente selecionador. Seguindo o princípio da seleção natural de Darwin, o autor desenvolveu o que chamou de "seleção pelas consequências" (Skinner, 1981/2007). Em substituição ao modelo causal mecanicista vigente entre 1930 e 1938 (Micheletto, 2001), Skinner afirma a existência de três níveis de seleção para explicar a origem do comportamento humano: filogenético, ontogenético e cultural. No primeiro, no segundo, e no terceiro nível, respectivamente, os comportamentos são determinados por um ambiente que mantém características típicas da espécie (importantes para sua sobrevivência), contingências de reforçamento (comportamentos serão selecionados a partir das consequências que produzem) e práticas culturais a serem passadas às próximas gerações. Sobre o terceiro nível (cultural), Skinner escreveu:

É o efeito sobre o grupo e não as consequências reforçadoras para seus membros, o responsável pela evolução da cultura. Em suma, então, o comportamento humano é o produto conjunto de a) contingências de sobrevivência responsáveis pela seleção natural das espécies, e b) contingências de reforçamento responsáveis pelos repertórios adquiridos por seus membros, incluindo c) contingências especiais mantidas por um ambiente cultural evoluído. (p.131)

Ainda que um grupo necessariamente seja formado por indivíduos que se comportam (e somente eles é que se comportam), para a sobrevivência de práticas culturais, são os efeitos sofridos pelos indivíduos enquanto grupo e não individualmente que determinam a evolução de uma cultura e suas práticas.

Em suas investigações, Skinner (1953/2003) se interessou e pesquisou primordialmente o segundo nível de seleção, nível este que se refere ao comportamento operante. $\mathrm{O}$ autor afirma que o comportamento operante ocorre em função de seus antecedentes e consequências. Isto quer dizer que respostas emitidas sob controle de um antecedente que sinaliza a ocorrência de reforçamento têm sua probabilidade de emissão aumentada, enquanto respostas que produzem consequências aversivas ou perda de reforçadores têm sua probabilidade de ocorrência futura diminuída. Ele defende também 
que no momento em que os indivíduos de uma determinada espécie adquirem comportamentos operantes adaptados a ambientes específicos, a seleção em nível ontogenético é capaz de sobrepor àquela ocorrida em nível filogenético. $\mathrm{O}$ autor exemplifica sua fala, da seguinte forma: quando indivíduos de uma espécie emitem comportamentos selecionados primeiramente pelo nível filogenético (e.g. alimentação e cópula), tais atividades têm valor de sobrevivência, mas não necessariamente, valor reforçador. Ou seja, comer determinado alimento ou ter comportamentos sexuais com determinada parceira ou parceiro em dado momento não terão obrigatoriamente valor reforçador inicialmente para o sujeito. Entretanto, no momento em que essas respostas (anteriormente apenas como um produto da seleção natural) passam a ser mantidas pelas consequências que produzem, tais indivíduos podem comer alimentos diferentes em contextos distintos e ter contato sexual além da procriação, como fruto do condicionamento operante. Dessa forma,

Uma vez que uma espécie que rapidamente adquire comportamentos apropriados a ambientes específicos tem menor necessidade de um repertório inato, o condicionamento operante poderia não apenas suplementar a seleção natural do comportamento, mas também substituí-la. Houve vantagens que favoreceram esta mudança (Skinner, 1981/2007, p.130).

Além dos dois níveis de variação e seleção já citados, qualquer indivíduo inserido em uma sociedade está sujeito ao terceiro nível, o cultural. É neste último nível que se encontram as práticas culturais de uma sociedade. Para o planejamento de práticas culturais e a compreensão do motivo que faz com que as pessoas se comportem como e quando se comportam é essencial analisar de maneira integrada estes três níveis de seleção (Sousa \& Carrara, 2013). Foi Skinner (1981/2007) quem trouxe este tipo de consideração (de que comportamentos são determinados pelos três níveis de variação e seleção), mas desde 1986, o conceito de Metacontingência desenvolvido por Sigrid Glenn contribui para o estudo das práticas culturais (Andery \& Sério, 2005). Entendendo a dinâmica de que a cultura e suas práticas sobrevivem a partir de consequências que 
retroagem sobre o grupo, mas que um grupo é formado por indivíduos e são somente indivíduos que se comportam, fica evidente que toda e qualquer investigação realizada sobre o comportamento requer uma análise dos três níveis de seleção (Skinner, 1953/2003; Todorov, 2012, 2013).

O interesse da Análise do Comportamento é o estudo do comportamento de animais humanos e não humanos em todos os seus princípios e variáveis que os influenciam (Skinner, 1953/2003), mas em geral, a finalidade última é analisar o comportamento humano. Cada comportamento emitido por um indivíduo ocorre em um contexto formado por um ambiente físico que, muitas vezes, é composto de outras pessoas. $\mathrm{O}$ ambiente selecionador de um comportamento pode tanto ser o ambiente físico quanto as outras pessoas presentes. Essa premissa pressupõe que o comportamento de um indivíduo serve como ocasião para o comportamento de outro. Conforme Sampaio e Andery (2010), para que a Análise do Comportamento possa entender o comportamento de maneira ampla, é preciso tratar de fenômenos sociais. Fenômenos sociais podem ser entendidos como eventos que envolvam ao menos duas pessoas que se comportem de maneira relacionada. Muito embora fenômenos sociais sejam conhecidamente foco de interesse de outras áreas como a antropologia, economia, psicologia social e sociologia, eles têm sido pesquisados por analistas do comportamento desde Walden two, de Skinner, em 1948 (Vichi, 2004). Investigações sobre o tema têm sido feitas frequentemente por meio de metodologias adaptadas de experimentos clássicos na área social, como o dilema dos comuns (Hardin,1968) e o dilema do prisioneiro (Tucker, 1983).

Skinner (1953/2003) define o comportamento social como comportamento de pelo menos dois indivíduos, um em relação ao outro ou juntos em relação a um ambiente comum. No mesmo livro, Ciência e Comportamento Humano, ele afirma: "é o indivíduo que se comporta. O problema apresentado pelo grupo maior é explicar por que os indivíduos se comportam juntos.” (p.340). Considerando o valor teórico e pragmático das 
práticas culturais, Skinner discute a importância do analista do comportamento na previsão, controle e modificação de tais práticas no contexto social (Sousa \& Carrara, 2013).

\section{Comportamento Social e Metacontingência}

A partir de seu claro interesse no nível ontogenético, Skinner (1953/2003) definiu a tríplice contingência como unidade básica de análise do comportamento operante. Mesmo com uma proposta eficaz em seu objetivo (estudar, analisar e explicar o comportamento operante), de acordo com que o próprio Skinner (1953) afirmou e foi reiterado por Glenn quando o termo metacontingência foi definido em 1986, a contingência tríplice não se mostra ser suficiente para análises e estudos profundos sobre práticas culturais. Fica, a partir da argumentação de Skinner, a dúvida se haveria ou não diferença entre os princípios básicos do comportamento emitido de maneira individual ou em grupo, no sentido de várias pessoas se comportando. Uma vez que o comportamento, por definição, é individual com base na premissa de que quem se comporta é sem dúvidas o indivíduo, o uso do termo "comportamento social” só se justifica quando este carregar propriedades específicas que a definição de comportamento operante e da contingência tríplice não sejam capazes de abordar (Sampaio \& Andery, 2010).

Em Walden two (1948), Skinner propõe uma comunidade organizada em contingências planejadas em prol da sociedade. Este foi o primeiro momento em que ele demonstrou preocupação com uma ciência do comportamento favorável ao planejamento cultural. Apesar disso, este aspecto (comportamento social) parece ter ficado à margem dos interesses principais da Análise Experimental do Comportamento (Moreira, Martone \& Todorov, 2005). Sobre o assunto, Moreira, Martone e Todorov (2005), afirmam que "o foco principal sempre será o indivíduo, mas será que existe algo mais a ser considerado quando o ambiente do indivíduo é um grupo social?” (p. 10). 
Sigrid Glenn, em 1986, cunhou o termo "Metacontingência" como uma alternativa ao problema trazido por Skinner. (Moreira, Martone \& Todorov, 2005). Ela atribuiu ao conceito de "relações contingentes entre uma classe de classes operantes e uma consequência cultural comum" (p. 3) o nome "Metacontingência" para diferenciar das contingências tríplices inseridas na história de reforçamento dos indivíduos. $\mathrm{O}$ conceito de metacontingência traz consigo a ideia de contingências entrelaçadas e produto agregado (PA) (Glenn, 1988; Andery, Micheletto \& Sério, 2005; Todorov, 2010, 2012). Para a autora do conceito, a metacontingência seria a unidade de análise ideal para descrever os eventos inseridos nas relações entre classes de operantes, cada qual produzindo consequências individuais e uma consequência ocorrida em longo prazo, mediada socialmente e compartilhada por todos os operantes envolvidos nas contingências individuais (e.g. contingências entrelaçadas), bem como os produtos decorrentes da relação (entrelaçamento) entre as contingências individuais (Glenn, 1986; 1988).

Desde sua criação, o conceito de metacontingência vem sofrendo alterações e/ou redefinições a fim de unificar seu uso na análise do comportamento (Martone \& Todorov, 2007; Todorov, 2012). Todorov acrescenta que embora o uso do conceito seja feito em sua maioria por analistas do comportamento para fazer referência às práticas culturais que envolvem consequências determinadas às pessoas ou grupos, passou-se a utilizar este mesmo conceito para diversos fenômenos diferentes. Dessa forma, passou a ser tema de estudo de diversos autores (e.g. Azevedo, 2015; Andery \& Sério, 1997; Andery, Micheletto \& Sério, 2005; Glenn, 1986, 1988; Houmanfar \& Rodrigues, 2006; Martone, 2008; Martone \& Todorov, 2007; Naves \& Vasconcelos, 2008; Todorov, 1987, 2009, 2010, 2012; Vasconcelos, 2014; Vichi, 2004).

Houmanfar e Rodrigues (2006) afirmam a relação entre produto agregado e contingências entrelaçadas como uma analogia à relação entre comportamento operante 
e reações fisiológicas. Variações em neurônios, glândulas, hormônios e grupos musculares estão presentes durante a emissão de qualquer comportamento operante, mas não fazem parte da análise funcional. O simples acúmulo de reações fisiológicas não produziria a consequência que seleciona o operante analisado. Da mesma forma, sabe-se que contingências comportamentais individuais fazem parte de uma metacontingência, mas não são o foco da análise, uma vez que é preciso mais do que a simples soma de eventos individuais para se caracterizar uma metacontingência (Todorov, Moreira \& Moreira, 2005). Na comparação à contingência de três termos, Houmanfar e Rodrigues (2006) distribuem os termos da metacontingência da seguinte forma: o meio cultural (recursos, costumes e regras de uma sociedade) seria o termo antecedente, o produto agregado ficaria no lugar da resposta e os efeitos produzidos por essa relação seriam as consequências (Glenn, 2004; Houmanfar \& Rodrigues, 2006).

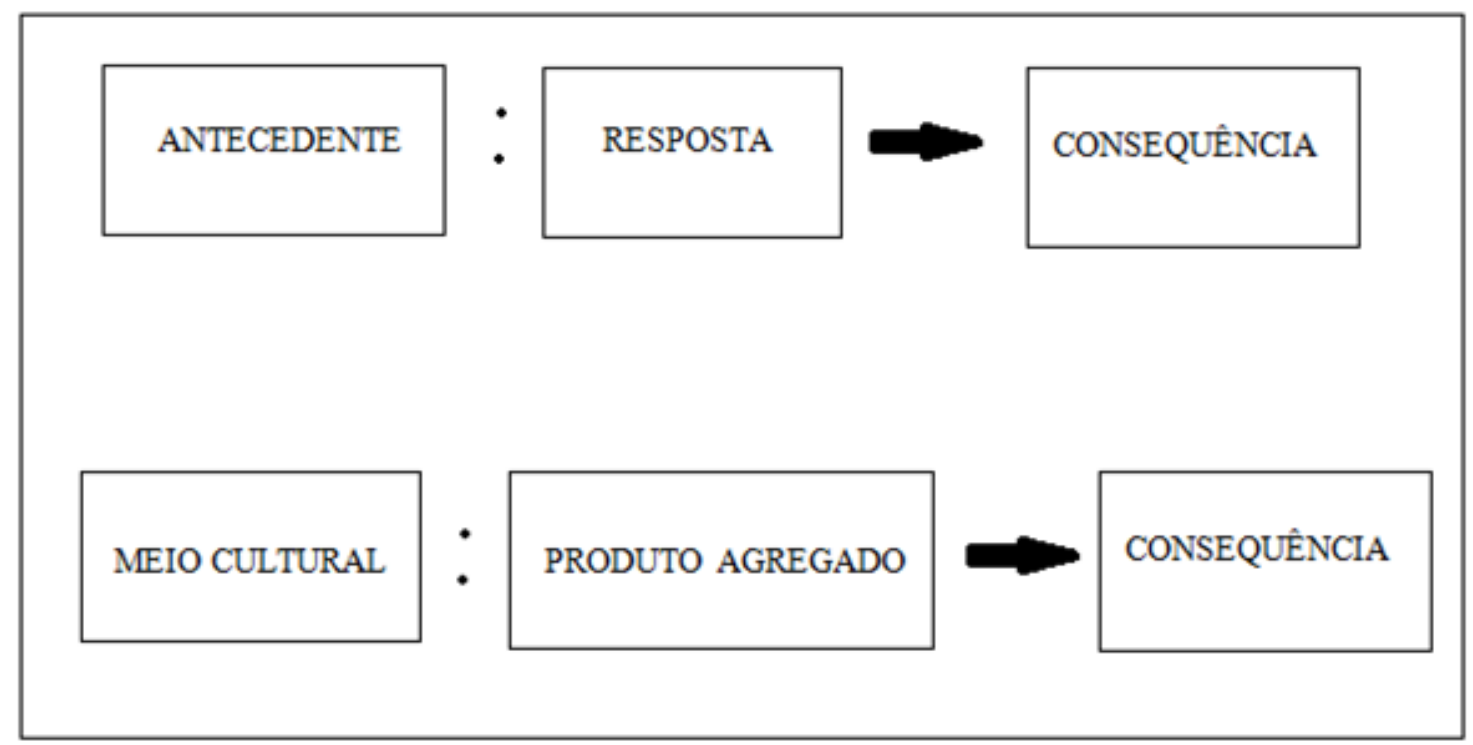

Figura 1. Comparação entre contingência operante e metacontingência. Enquanto na contingência operante o estímulo antecedente fornece condição para a ocorrência da resposta selecionada por sua consequência, na metacontingência, é o meio cultural quem serve de ocasião para a ocorrência do produto agregado e de sua seleção pela consequência produzida.

Os produtos agregados são formados pelo entrelaçamento de contingências individuais e selecionados pelas consequências que os sucedem (Todorov, 2012, 2013). Houmanfar e Rodrigues (2006), Houmanfar, Rodrigues e Ward (2010) e Todorov (2012) 
argumentam que em vez de contingências comportamentais entrelaçadas (CCEs) serem selecionadas pelas consequências em uma metacontingência, na verdade, o que ocorre é a seleção do PA. Assim, "metacontingências envolvem essencialmente contingências socialmente determinadas" (Todorov, 1987, p. 10), sendo um conjunto de contingências individuais que se entrelaçam e formam um produto agregado que poderá ser selecionado pelo contexto cultural em que ocorreu, mesmo que haja variabilidade nas CCEs, mantendo constante o PA (Glenn, 1986; Houmanfar \& Rodrigues, 2006; Malott \& Glenn, 2006; Sampaio \& Andery, 2010). Uma situação para exemplificar o ponto de vista de Houmanfar e Rodrigues (2006), Houmanfar, Rodrigues e Ward (2010) e Todorov (2012) seria um casal que faz um jantar para receber os amigos em casa. As tarefas concernentes ao jantar desempenhadas pelos membros do casal seriam as contingências comportamentais entrelaçadas e o jantar propriamente dito seria o produto agregado. A partir do jantar produzido e os efeitos obtidos, por exemplo, elogios por parte dos amigos, amigos repetirem o prato, é provável que o jantar se repita em situações semelhantes.Independente da configuração das contingências individuais, é o jantar que é selecionado - ou seja, não importa quem cortou a cebola ou quem pôs a mesa, por exemplo, desde que o jantar, enquanto um produto final, seja repetido (Houmanfar \& Rodrigues, 2006; Houmanfar, Rodrigues \& Ward, 2010; Todorov, 2012). Não se busca a partir deste raciocínio negar a importância das contingências comportamentais entrelaçadas, bem como a influência das consequências produzidas por elas, uma vez que tenderão a se repetir de alguma maneira. Porém, não é este o ponto principal da seleção em uma metacontingência (assim como no comportamento operante em que respostas fisiológicas estão presentes em todo o tempo, mas também não são o foco da seleção operante).

A importância de outro nível de análise dos comportamentos emitidos no contexto social está no fato de que é a partir deste contexto que diversos comportamentos são 
aprendidos e mantidos, produzindo consequências que indivíduos se comportando de maneira isolada não poderiam produzir (e.g. comportamento cooperativo $\mathrm{e}$ comportamento verbal; Andery \& Sério, 2005; Naves \& Vasconcelos, 2008).

\section{Estudos Experimentais em Metacontingência}

Assim como ocorre com o comportamento operante e as contingências tríplices utilizadas em sua descrição, o "comportamento social" (Skinner, 1953/2003) e as metacontingências envolvidas devem também ser empiricamente investigados. Vichi (2004) realizou o primeiro estudo sobre metacontingência em análise experimental do comportamento. Este estudo foi importante porque abriu o espaço para o estudo do comportamento de indivíduos em sociedade dentro da análise do comportamento, conforme Skinner (1953) sugeriu, e não mais como uma vertente exclusiva à Psicologia Social e a outras ciências sociais.

Para Skinner (1953/2003), a Psicologia, como uma ciência natural, deveria estudar fenômenos naturais - isto é, todo e qualquer fenômeno relativo ao comportamento. Até a descrição do conceito de metacontingência (Glenn, 1986), no entanto, analistas do

comportamento dedicaram a maior parte da produção de conhecimento ao comportamento emitido em contingências individuais, deixando aquilo que fosse concernente ao social, para a Psicologia Social e áreas afins.

Mesmo com a existência de trabalhos na área (e.g., Andery, Micheletto \& Sério, 2005; Naves \& Vasconcelos, 2008; Vichi, 2004) ainda é inconsistente a metodologia de estudos em metacontingência. Os experimentos que abordam a Metacontingência como tema têm sido realizados envolvendo aspectos do que chamam de "comportamento de jogo", onde as respostas emitidas por indivíduos em dupla produzem diferentes combinações com efeitos diversos sobre o PA enquanto estratégias de competição ou cooperação, e a manipulação de diferentes variáveis relacionadas à metacontingência (i.e. 
magnitude do reforço, contingências entrelaçadas e gerações de participantes; Azevedo, 2015; Martone, 2008; Pereira, 2008; Vasconcelos, 2014; Vieira, 2010).

Martone (2008) replicou o experimento de Vichi (2004), com o objetivo adicional de observar padrões nas CCEs. O experimento de Vichi (2004) consistiu em um jogo de apostas realizado em grupo. Jovens universitários foram divididos em dois grupos e cada um dos participantes recebeu uma quantidade de fichas a serem utilizadas durante as jogadas. Ao final do experimento, os participantes poderiam trocar suas fichas por dinheiro. Cada componente do grupo poderia decidir quantas fichas queria gastar em cada aposta, mas era realizada uma aposta única por tentativa que deveria representar todo o grupo. Os participantes escolhiam uma linha da matriz de $8 \times 8$ e o experimentador escolhia uma coluna. Se na célula interseccionada constasse o sinal “+”, o grupo ganhava o dobro das fichas apostadas e, caso a célula tivesse o sinal “-”, o grupo ganhava apenas metade das fichas. O critério para a escolha do experimentador era o tipo de divisão (ou colaboração com fichas de cada participante) das fichas por parte dos participantes do grupo em cada aposta realizada pelo grupo (de maneira igual ou desigual) e variava conforme as condições (A e B). Na condição A, somente quando os participantes dividiram as fichas de maneira igualitária, obtiveram reforçamento (“+”) e na condição B, só foram reforçadas respostas emitidas após as tentativas em que a divisão de fichas foi realizada de maneira desigual entre os componentes do grupo. Verificou-se que foi selecionada a maneira de obter ganhos nas duas condições experimentais, ou seja, na condição em que foi reforçada a divisão igualitária, este padrão se repetiu e na condição em que foi reforçada a distribuição desigual, os participantes emitiram novamente estas respostas.

Com o objetivo de verificar diferenças na manipulação de consequências para o indivíduo ou para o grupo, Pereira (2008) utilizou em seu procedimento consequências individuais e consequências para o grupo. O procedimento consistiu em um jogo de 
computador contendo oito células (quadrados vazios a serem completados por números) divididas em duas linhas. Em cada tentativa, cada célula da primeira linha continha um número entre 0 e 9 , e os participantes deveriam completar os números das células da linha posterior. Pontos foram utilizados como reforçadores. As consequências individuais eram contingentes à soma dos números das colunas formadas pelas linhas (total de quatro colunas). Os participantes ganhariam pontos quando a soma de cada coluna resultasse em um número ímpar; caso uma delas resultasse em um número par, os participantes perdiam pontos. As consequências para o grupo eram contingentes ao total da soma de pontos de todos os participantes. Além disso, o participantes foram trocados em rodadas. Essas trocas foram chamadas de gerações. O experimento não demonstrou dados sistemáticos para este tipo de manipulação (consequências individuais como variável independente), não apresentando mudanças correlacionadas ao uso de consequências individuais como variável independente.

Outra variável investigada nos experimentos sobre metacontingência foi o controle discriminativo. Nos trabalhos desenvolvidos por Vieira (2010) e Azevedo (2015) foi utilizada como estímulo discriminativo a cor da tela do fundo do computador. $\mathrm{Na}$ condição em que havia a presença do estímulo discriminativo, as duplas deveriam se comportar a fim de realizar o encontro entre as peças. Vieira (2010) retomou o procedimento realizado por Pereira (2008); Azevedo (2015), por sua vez, utilizou um procedimento semelhante ao de Vasconcelos (2014), que investigou a modelagem de encontros (PA) em um tabuleiro de xadrez virtual. No procedimento de Vasconcelos (2014) e Azevedo (2015), parâmetros eram previamente estabelecidos em um jogo de xadrez virtual, em que os participantes deveriam realizar o encontro entre duas peças que se movimentavam seguindo o movimento tradicional da peça "cavalo" do jogo de xadrez (movimento em "L"). Quanto ao controle discriminativo, os dados de Pereira (2008) e 
Azevedo (2015) sugeriram ter havido controle discriminativo por parte do procedimento realizado

Os trabalhos de Vichi (2004), Martone (2008), Pereira (2008) e Vieira (2010) utilizaram o reforçamento de respostas individuais, além do reforçamento para as respostas emitidas em grupo, e muitas vezes os procedimentos foram complexos e de difícil compreensão. Martone (2008), em seu experimento demonstra as dificuldades encontradas ao replicar o que foi realizado por Vichi, em 2004. Procedimentos que exigem treino prévio dos participantes para a realização da tarefa, bem como reforçamento extra, disposto individualmente, podem tornar replicações mais difíceis, acarretando em menor produção de conhecimento do que se as replicações diretas e sistemáticas acontecessem com maior frequência. Vasconcelos (2014) defende que manipulações mais simples podem facilitar a análise experimental de uma metacontingência. Até os trabalhos de Vasconcelos, em 2014, e Azevedo, em 2015, não haviam sido feitas manipulações apenas com reforçamento social (que naturalmente fazem parte de uma interação social), sem o uso de reforçamento como pontos e/ou dinheiro também para as respostas individuais. Seguindo o que foi defendido por Vasconcelos, em 2014, espera-se que experimentos em pesquisa básica possam acontecer sem perdas na transição do ambiente natural para o laboratório, uma vez que este tipo de pesquisa tem a grande vantagem de poder isolar diversas variáveis que em contextos naturais não é possível. Muitas vezes, o que um analista do comportamento quer ao realizar pesquisa básica é que o conhecimento obtido sirva como possível parâmetro para a pesquisa aplicada e não que seja uma extrapolação forçada de um achado laboratorial.

Como visto, são notáveis as dificuldades na replicação e no estudo experimental de práticas culturais, devido a divergência conceitual já mencionada no uso do termo Metacontingência e a falta de metodologia padrão para o estudo do tema. As dificuldades no estudo destas práticas se mostram principalmente no que tange a um procedimento 
experimental bem estabelecido e na identificação de variáveis dependentes e independentes envolvidas no processo como um todo (Azevedo, 2015; Vasconcelos, 2014). Quando uma área de pesquisa é firmada, é importante que a metodologia e as variáveis estudadas sejam consistentes para que diversos trabalhos possam transcender entre si, favorecendo a produção de conhecimento e o crescimento da ciência. Diante do exposto, percebe-se a importância do estabelecimento de estratégias e metodologias padronizadas para o estudo de temáticas envolvendo o conceito de metacontingência e/ou práticas culturais. Em busca de padronização, é relevante que se pesquise sobre novos procedimentos e/ou se replique procedimentos já utilizados para que se possa determinar padrões e regularidades em sua aplicação.

\section{Aquisição Repetida}

Parte da ciência procura fenômenos em que as metodologias sejam pautadas em estados estáveis (Todorov, 1983), ou seja, inúmeros experimentos feitos buscam justamente o estado estável de determinada variável dependente. O fenômeno chamado de estado estável foi descrito por Sidman (1960) como um estado equilibrado entre as respostas emitidas pelo organismo e as variáveis das quais elas são função. Portanto, a busca pela estabilidade pode ser entendida como a busca pelo controle de variáveis importantes envolvidas em determinado processo comportamental. Fala-se em critério de estabilidade quando se encontram requisitos que são chamados de estáveis por estarem presentes em diversas condições em que determinado comportamento ocorre. Dessa forma, diz-se que uma nova resposta foi adquirida. Por exemplo, diz-se que uma criança sabe somar quando ela emite o comportamento de somar diante de uma conta de soma, por diversas vezes (o número de vezes é estabelecido, seguindo critérios encontrados na literatura ou em padrões estabelecidos pelo pesquisador). Contudo, investigando apenas estados estáveis no processo de aprendizagem, possivelmente variáveis importantes como 
os estados de transição serão ignoradas. Voltando ao exemplo anterior, apenas considerando as respostas certas emitidas pela criança quando esta aprende a somar, é possível que se perca fenômenos importantes ocorridos durante a aprendizagem (como as estratégias utilizadas pela criança).

Skinner (1968) defende que a aprendizagem é um processo de constante mudança, uma vez que um indivíduo aprende por toda a sua vida. Arranjar contextos favoráveis à aprendizagem significa fornecer ocasião para o uso das habilidades a serem adquiridas, estabelecendo condições para que este comportamento se repita, sempre que preciso (podendo-se então, dizer que foi aprendido). Para avaliar a aprendizagem de novas habilidades, é comum a utilização de metodologias de pesquisa que envolvam o uso de linha de base, a fim de comparar e avaliar o nível de desempenho antes e depois de determinada intervenção. Normalmente uma intervenção é caracterizada pela introdução ou retirada de variáveis candidatas a explicar o fenômeno estudado (Velasco, GarciaMijares \& Tomanari, 2010).

O repertório de um indivíduo é adquirido e modelado ao longo de toda sua história de aprendizagem; portanto, estados transicionais, e não apenas estados estáveis, estão presentes ao longo da vida do indivíduo. Todorov (1983) afirma que, após a definição de um critério de estabilidade, a problemática é investigar quais condições fazem o organismo emitir tais respostas com menor custo, sem perder reforçamento. Para a investigação da aprendizagem contemplando estados de transição,o autor afirma que é possível o uso de grupos de sujeitos e delineamentos estatísticos, ou a utilização da análise experimental do comportamento no estudo de aquisições repetidas.

Procedimentos de aquisição repetida avaliam uma nova aprendizagem a cada condição, pois as contingências para o reforço mudam em cada nova condição. Assim, cada sujeito é exposto a todas as condições experimentais, o que possibilita trabalhar com linhas de base comparáveis, intrassujeitos. Trabalhar com o delineamento intrassujeitos, 
em comparação ao delineamento de grupos, permite que se elimine a variabilidade entre os sujeitos que compõem o grupo, e favorece a análise de processos verdadeiramente comportamentais (uma vez que o comportamento diz respeito a indivíduos, e não a grupos). Pode-se por meio desta metodologia comparar um padrão de aprendizagem obtido entre condições (Gimenez \& Vasconcelos, 1999), além do fato de que este procedimento também permite que o experimentador analise de maneira diversificada a influência da variável independente sobre a variável dependente, uma vez que o sujeito experimental está sendo exposto sempre a uma nova condição (Santos, 2010).

O procedimento de Aquisição Repetida foi desenvolvido por Boren, em 1963 (Boren e Devine, 1968; Thompson, 1971; Hursh, 1977) e foi consolidado na área experimental por meio de estudos realizados sobre os efeitos de substâncias farmacológicas e/ou lesões cerebrais, utilizando-se principalmente de animais nãohumanos como sujeitos (Bickel, Higgins \& Griffiths, 1989; Bickel, Higgins \& Hughes, 1991; Harting \& McMillan, 1976; Higgins, Woodward \& Henningfield, 1989; Moerschbaecher, Boren, Schrot \& Fontes, 1979; Moerschbaecher \& Thompson, 1980; Peele \& Baron, 1988; Thompson, 1973, 1974, 1975, 1980; Thompson \& Moerschbaecher, 1980, 1981; Thompson, Moerschbaecher \& Winsauer, 1983) e respostas emitidas em sequência (Boren, 1969; Boren \& Devine, 1968; Kelly, Fischman, Foltin \& Brady, 1991; Santos, 2010; Schrot, Boren \& Moerschbaecher, 1976; Snodgrass \& McMillan, 1989). O estudo de aquisições repetidas tipicamente envolve a aprendizagem de uma sequência de respostas onde a sequência correta é alterada a cada condição, o que resulta em uma nova aprendizagem em cada um desses momentos. Usualmente esta metodologia serve como alternativa para medir o que, dentre possíveis variáveis, pode influenciar a aprendizagem diminuindo o número de erros cometidos pelos participantes. 
No experimento de Boren e Devine (1968), o procedimento de aquisição repetida de sequências de respostas foi utilizado. A tarefa dos sujeitos (macacos) era pressionar sequencialmente chaves iluminadas. A cada nova condição, a sequência exigida para o reforço era mudada. Como variáveis independentes, os pesquisadores empregaram o tempo em que os participantes ficavam em timeout como consequência de respostas incorretas, e a presença de uma luz com função sinalizadora de qual era chave correta a ser pressionada entre as condições. Os resultados do experimento demonstraram maior eficácia para diminuição de erros para o uso de timeout em detrimento do uso de luz com função discriminativa, ou seja, os participantes emitiram menos erros na condição em que o timeout foi utilizado do que a luz sinalizadora.

Outros estudos envolvendo aquisição repetida enquanto procedimento foram feitos sobre estados de transição (Thompson, 1971), reforço condicionado (Hursh, 1977), discriminação condicional (Moerschbaecher, Boren \& Schrot, 1978; Snodgrass \& McMillan, 1989), comportamento governado por regras (Vaughan, 1985), radiação ionizante (Vasconcelos, 1999) e investigação de variáveis que afetam a aprendizagem humana por meio de um software (Dermer \& Dermer, 2000). Algumas poucas pesquisas sobre o tema foram realizadas com crianças com desenvolvimento neurotípico e atípico (Santos, 2010). Vaughan (1985) utilizou em seu procedimento, uma tarefa onde as crianças precisavam aprender uma sequência de quatro respostas. Seu experimento foi dividido em modelagem e instrução. Durante a fase de modelagem, as luzes acima dos botões permaneciam acesas até que a resposta correta fosse emitida. Já durante a fase de instrução, acendia-se uma luz acima do botão cuja pressão seria reforçada (resposta correta). Santos (2010) estudou o padrão de desempenho de crianças diagnosticadas com TDAH que fazem e que não fazem uso de medicação, em tarefas virtuais de autocontrole. Tanto no procedimento de Vaughan (1985) como no de Santos (2010), após certo número de sessões, o número de erros e a taxa de respostas se tornou estável, proporcionando uma 
linha de base para a manipulação das variáveis independentes de interesse para cada estudo (e.g., uso de medicamentos). Assim, a utilização do procedimento de aquisição repetida como busca de definição de uma linha de base tem sido diversamente utilizada no estudo de variáveis que podem influenciar a aprendizagem de outras respostas (Miccione, 2009).

Tendo em vista a juventude do conceito de metacontingência, pouco se sabe sobre estados de transição que podem estar envolvidos. Uma vez que aquisições repetidas foram sugeridas (Todorov, 1989) para estudar os estados de transição de comportamentos operantes, por isso se torna relevante sua aplicação no estudo de práticas culturais. Trabalhos realizados recentemente (Azevedo, 2015; Vasconcelos, 2014) têm buscado demonstrar como os princípios do comportamento já estudados a partir da tríplice contingência (no caso, experimentos envolvendo modelagem e discriminação de estímulos) se dão em uma metacontingências

No presente trabalho, seguindo a linha de estudos de Vasconcelos (2014) e Azevedo (2015) sobre a investigação de princípios básicos do comportamento ao estudo de metacontingências, utilizou-se do procedimento de aquisição repetida para estabelecer as contingências de reforço presentes nas diferentes condições do experimento. Com base na necessidade de se ter experimentos padronizados em procedimentos e variáveis estudadas, para o estudo de práticas culturais, este trabalho visa descrever os efeitos de mudanças sucessivas na aprendizagem de um Produto Agregado em Metacontingências.

\section{Método}

\section{Participantes}

Participaram da pesquisa 20 adultos, dispostos em 10 duplas, estudantes de graduação do curso de Psicologia, de uma universidade particular do Distrito Federal, 
com idades entre 17 e 32 anos. A amostra foi definida por conveniência por meio de convites realizados em salas de aula. Sete duplas participaram na Condição 1 do experimento, e três duplas participaram na condição 2. Cada uma das duas condições foi composta por cinco fases. Cada dupla participou apenas de uma condição. A coleta foi realizada em uma instituição de pós-graduação em análise do comportamento. A pesquisadora entrou em contato com a instituição onde os dados seriam colhidos, munida de um termo de autorização para coleta de dados (Anexo 1) a ser assinado pelo responsável pela instituição. Os alunos interessados em participar assinaram uma lista passada em sala de aula, com horários disponíveis para a pesquisa e seus contatos (telefone e/ou email). As duplas foram estabelecidas com base na compatibilidade entre horários. Finalizado este processo, os participantes foram notificados com a data e horário estabelecidos para a sua participação no experimento, por meio de contato telefônico. Antes do início do experimento, os participantes foram solicitados a assinar o Termo de Consentimento Livre e Esclarecido (Anexo 2), fornecido pela pesquisadora. O projeto foi submetido ao CEP/IH Brasil para análise e aprovação?.

\section{Materiais e instrumentos}

A coleta de dados foi realizada em uma sala de aula de um instituto de pósgraduação particular de Brasília, equipada com mesa e carteiras. Os participantes se sentaram lado a lado em frente à mesa, e a experimentadora se sentou do lado oposto da mesa. Em cima desta, ficava o notebook para coleta de dados, com a tela virada para os participantes.

O experimento foi realizado com um notebook Lenovo®, processador Core i52410M CPU, 2.30GHz, 4GB de RAM, com sistema Microsoft Windows 8.1 Pro, equipado com o software "Xadrez" (Todorov \& Vianney, 2014). A atividade se deu em um tabuleiro virtual de 8x8 células de tamanho, semelhante ao tabuleiro de um jogo de xadrez 
(Figura 2), onde o objetivo dos participantes era promover o encontro das duas peças (uma amarela e uma vermelha), seguindo o movimento em "L" característico da peça cavalo no jogo de xadrez. O movimento em "L" deveria ser realizado individualmente pelas peças, e deveria respeitar a configuração de três por duas células em qualquer direção. Para realizar o movimento, o participante deveria clicar na célula do destino da peça e em qualquer direção, desde que respeitasse o limite de três por duas células para o movimento.

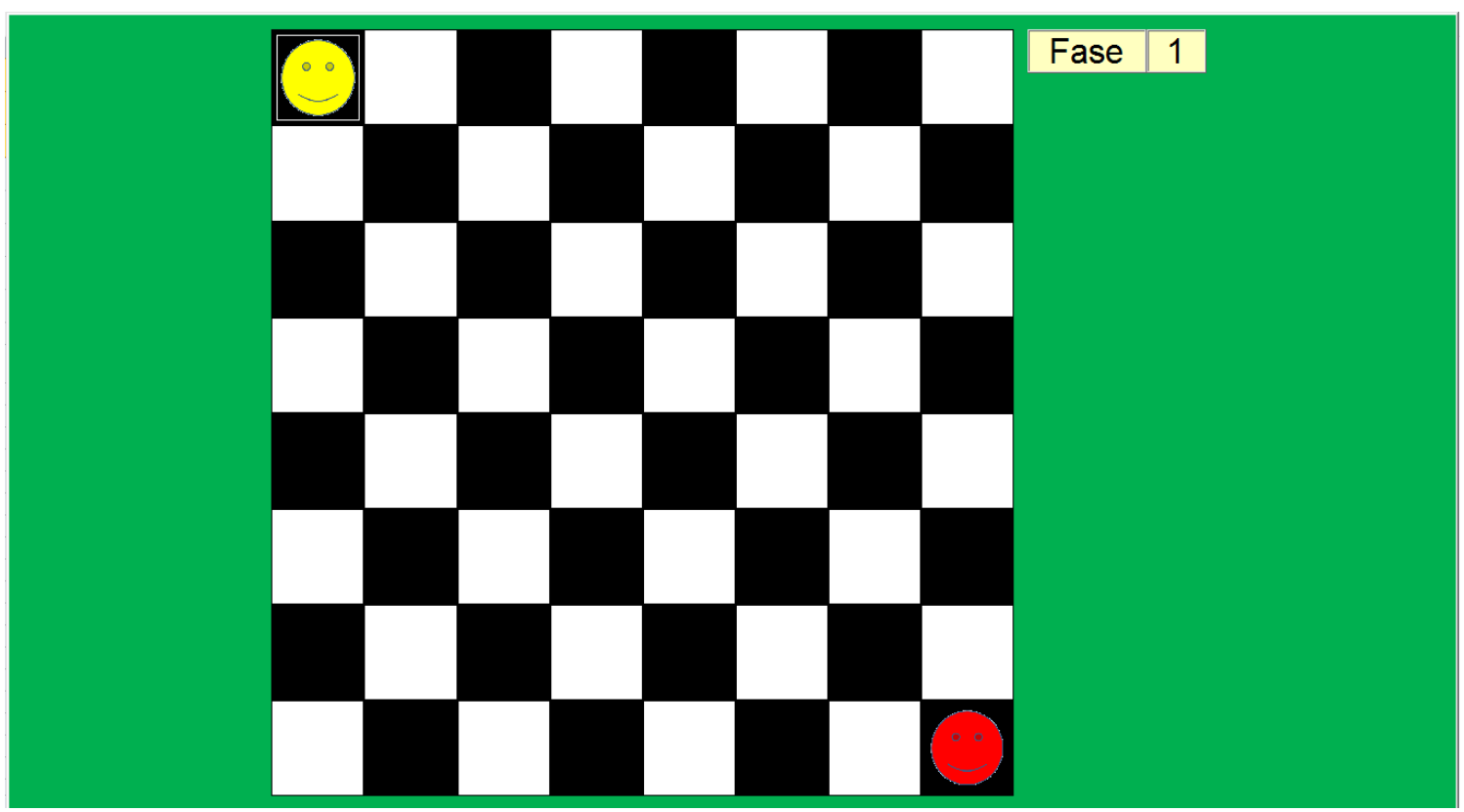

Figura 2. Tabuleiro do software "Xadrez", visível aos participantes. Todas as rodadas do jogo foram iniciadas pela peça amarela.

Sem o conhecimento dos participantes, o tabuleiro foi dividido em 16 quadrantes

(Figura 3), onde os encontros foram reforçados em diferentes condições.

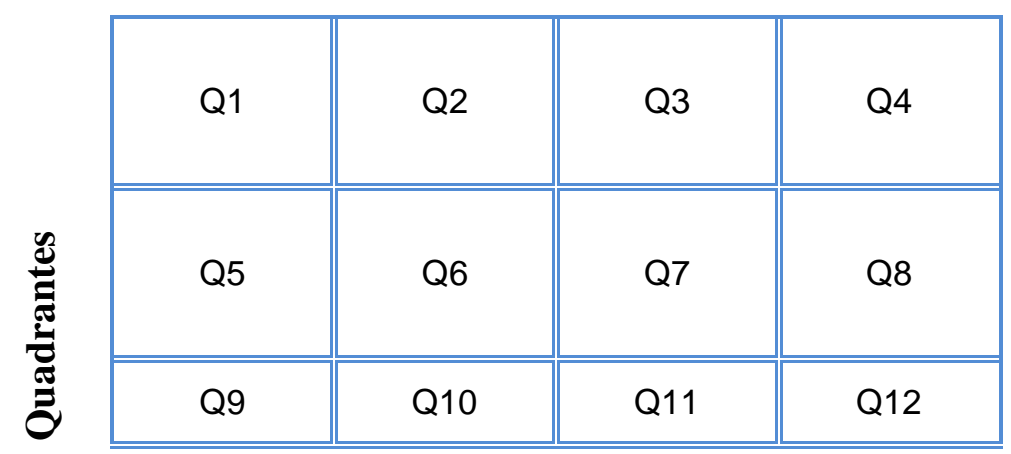




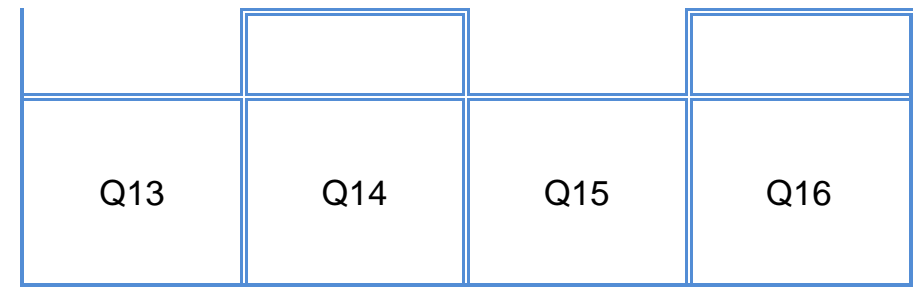

Figura 3. Divisão do tabuleiro em quadrantes. Cada célula composta com a letra "Q" e um número indica um dos quadrantes em que as peças poderiam se encontrar. Cada quadrante é formado por quatro células do tabuleiro virtual.

Os resultados do jogo (i.e., número de tentativas, acertos, erros, movimentos e o tempo decorrido na fase) foram gerados e armazenados em um output visível apenas à experimentadora disponível após a realização do experimento (Figuras 4, 5 e 6).

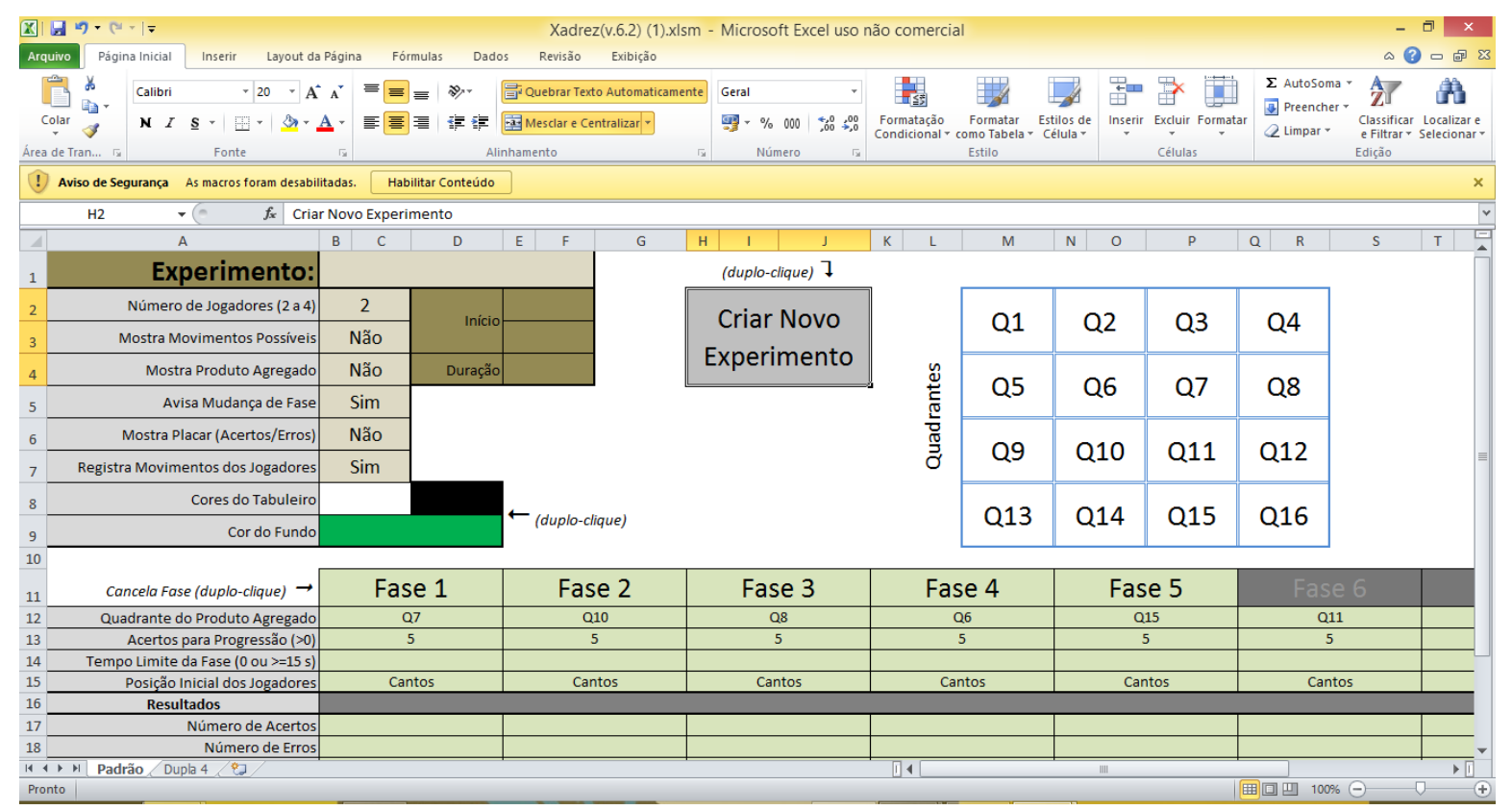

Figura 4. Output visível à pesquisadora na condição 1 . 


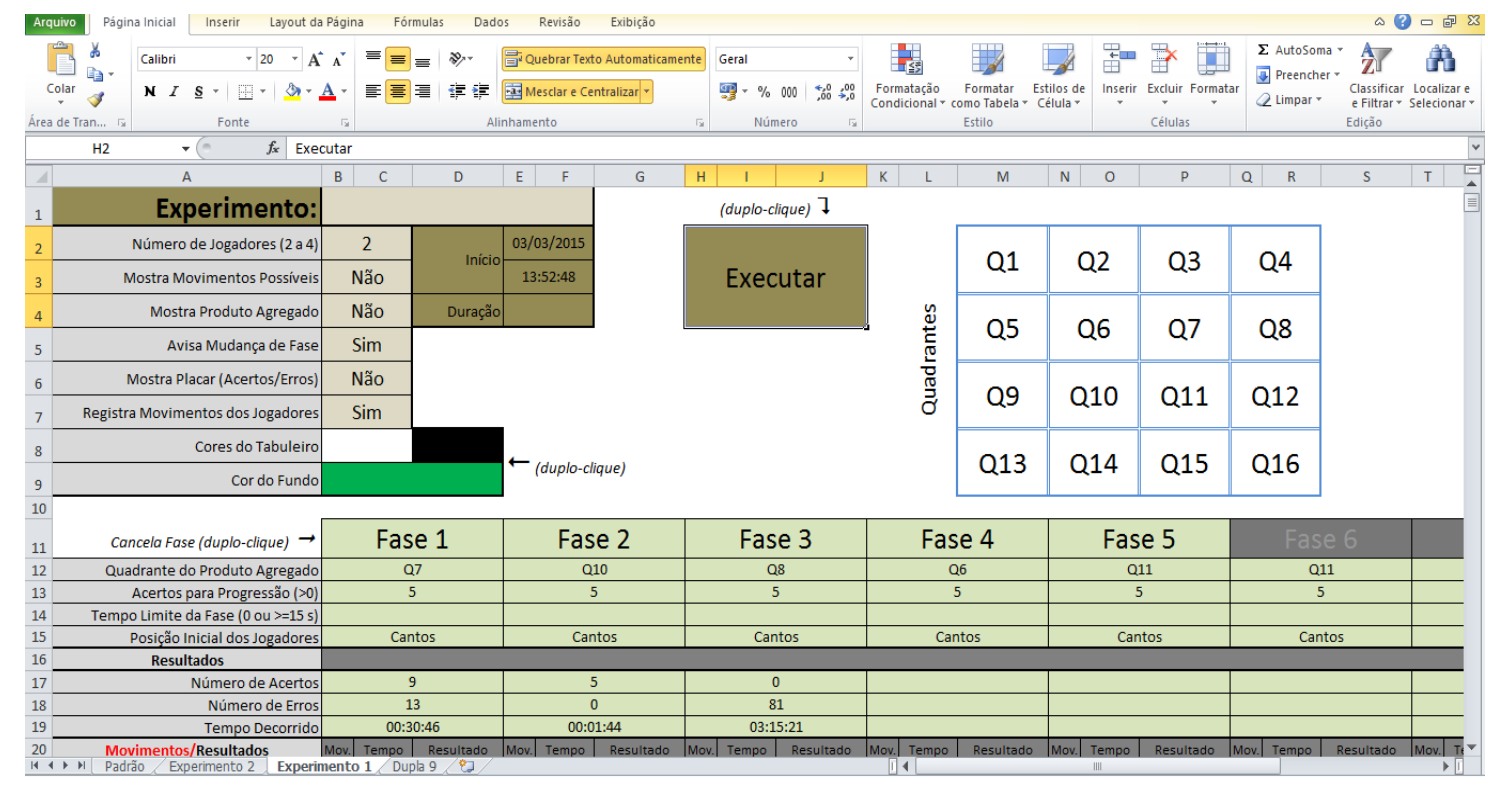

Figura 5. Output visível à pesquisadora na condição 2.

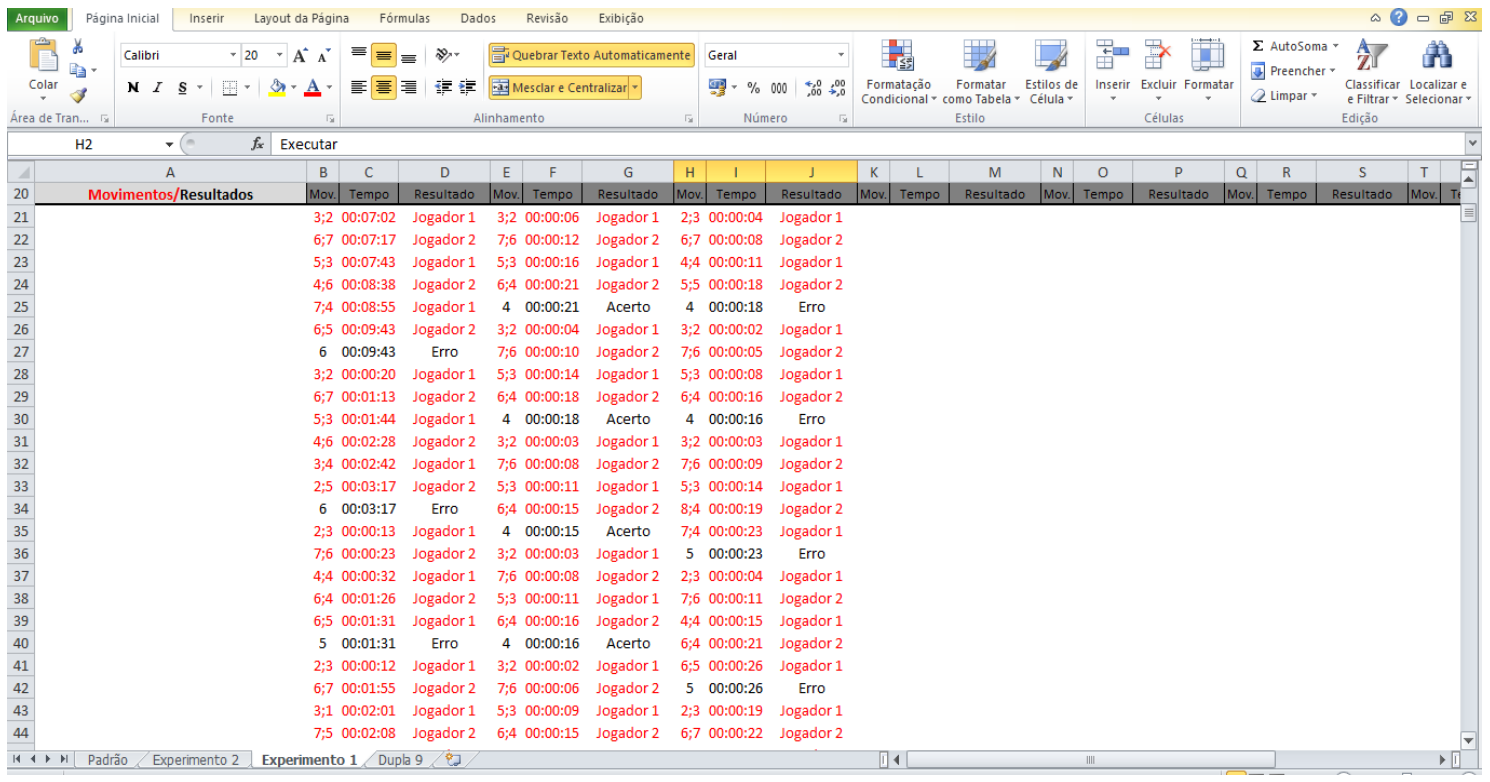

Figura 6. Dados dispostos no output visível à pesquisadora. Os dados em vermelho referem-se aos movimentos realizados pelas peças. Os "erros" são os encontros fora da localização previamente programada para o produto agregado e os acertos são os encontros reforçados (produto agregado).

\section{Procedimento}

Cada dupla participou apenas uma vez do experimento e em apenas uma das duas condições. O experimento foi executado em apenas uma sessão para cada dupla. Os participantes preencheram e assinaram o Termo de Consentimento Livre Esclarecido e, em seguida, receberam as seguintes instruções por escrito: 
Olá!

Vocês agora realizarão uma atividade juntos. Cada um de vocês terá uma peça colorida que deverá ser movimentada com toques no touch pad do notebook. Para movê-la basta dar dois toques rápidos na célula para qual você quer movimentar a peça. Cada peça se move fazendo um caminho em formato de " $L$ " (assim como o movimento da peça cavalo, no jogo de xadrez) em qualquer direção. Apenas assim é possível movimentar sua peça. As rodadas começam com as peças localizadas nos extremos do tabuleiro. Aquele jogador que ficar com a peça do canto superior esquerdo começa a rodada. As jogadas ocorrem de forma alternada e não é permitido "pular" a vez de nenhuma das peças. É permitido conversar sobre a atividade durante todo o período. A rodada termina quando as peças se encontram no tabuleiro. Ao final de cada uma das rodadas bem-sucedidas vocês receberão a seguinte mensagem: "PARABÉNS! O objetivo foi alcançado!’. O objetivo da atividade é vencer o máximo de rodadas possíveis. Quando o jogo acabar, vocês serão avisados.

Em caso de dúvidas, vocês podem consultar estas instruções a qualquer momento.

Decidam quem ficará com cada peça do tabuleiro.

Podemos começar?

Não foram dadas instruções verbais adicionais às instruções escritas. Em caso de dúvidas, os participantes foram orientados a ler as instruções novamente. Após a confirmação do entendimento do procedimento, foi iniciada a atividade e finalizada depois de ocorridas cinco fases. Foi permitido aos participantes o acesso a celular, relógio e demais objetos pessoais, bem como papel e caneta quando solicitado. Os participantes poderiam conversar durante todo o experimento. As rodadas consideradas vencidas (Figura 7) foram aquelas que estavam de acordo com os parâmetros previamente estabelecidos para cada fase, programados com o software utilizado. Em cada uma das cinco fases, os participantes deveriam produzir o PA em quadrantes diferentes para obter reforçamento, pré-determinados pela pesquisadora. Isto quer dizer que em cada fase, o PA seria reforçado em um local específico, delimitado nos parâmetros iniciais do procedimento (Fig. 8). Apenas contaram como acertos os encontros ocorridos dentro dessa limitação. Os participantes não tiveram acesso a esta informação. Para a mudança de fase, foi necessário que as duplas participassem de cinco tentativas sem erro, de forma 
consecutiva, de acordo com o critério definido para encontro (PA) das peças em tal condição. Não houve limite de tempo para o término de cada fase ou do experimento.

Cada tentativa era finalizada com a mensagem: "PARABÉNS! O objetivo foi alcançado" quando o encontro acontecia em um local pré-determinado ou com a mensagem "FINAL DA TENTATIVA. Tente outra vez" quando o encontro ocorria em um local que não produzia reforçamento; depois disso, as peças retornavam à posição inicial. Não era possível "pular a vez", de maneira que o movimento somente era permitido à peça da vez e deveria ser realizado pelo participante responsável por determinada peça. Caso os participantes clicassem em uma célula ilegal nada acontecia, as peças se moviam apenas se o duplo clique ocorresse em uma célula que respeitasse o critério de três por duas células.

Após a coleta de dados e os resultados obtidos na primeira condição, fez-se necessária outra coleta com a alteração da fase 5 do quadrante 15 para o quadrante 11 . A partir de então, esses dois momentos foram nomeados de Condição 1 e Condição 2. A Condição 2 diferiu da condição 1 apenas no quadrante onde o encontro seria reforçado, que passou do Q15 para o Q11 na Fase 5.

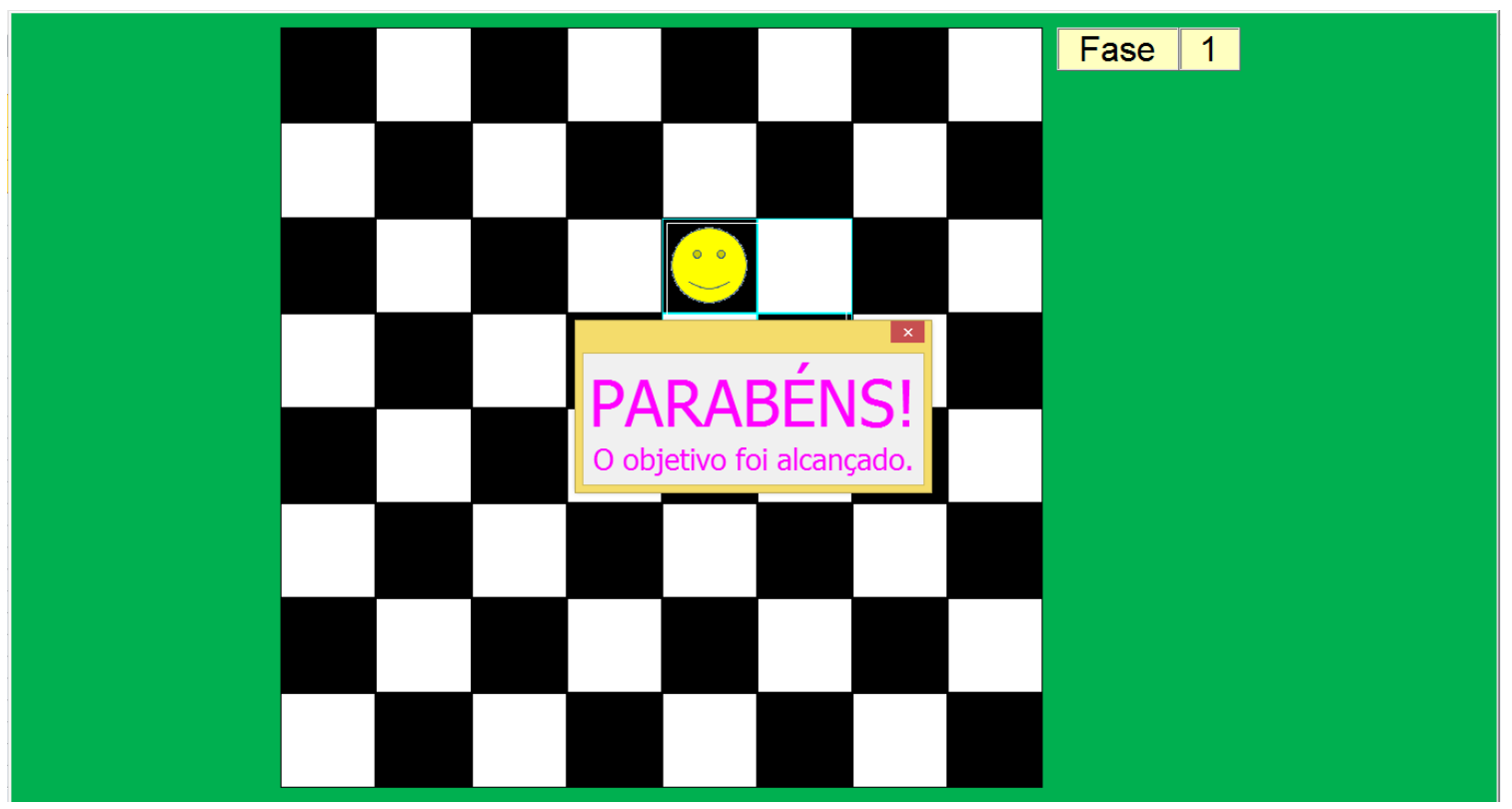


Figura 7. Tela do software quando o produto agregado foi produzido (reforçamento positivo social). Não houve reforçamento programado para as contingências individuais. Após a ocorrência de cinco acertos os jogadores passaram para a fase seguinte.

\begin{tabular}{|c|c|c|c|}
\hline $\begin{array}{c}\frac{\text { Saída da }}{\text { peca }} \\
\text { amarela }\end{array}$ & Q2 & Q3 & Q4 \\
\hline Q5 & Fase 4 & Fase 1 & Fase 3 \\
\hline Q9 & Fase 2 & $\begin{array}{c}\text { Fase } 5 \\
\text { (Condição 2) }\end{array}$ & Q12 \\
\hline Q13 & Q14 & $\begin{array}{c}\text { Fase } 5 \\
\text { (Condição 1) }\end{array}$ & $\begin{array}{c}\frac{\text { Saída da }}{\text { peça }} \\
\text { vermelha }\end{array}$ \\
\hline
\end{tabular}

Figura 8. Disposição dos quadrantes onde os encontros foram reforçados por fase, nas condições 1 e 2. Na Condição 1, foram programados para o PA nas fases 1, 2, 3, 4 e 5, os quadrantes Q7, Q10, Q8, Q6 e Q15, respectivamente. Na Condição 2, os quadrantes programados foram o Q7, Q10, Q8, Q6 e Q11 para as fases 1, 2, 3, 4 e 5, respectivamente. Note que entre as duas condições apenas o quadrante previsto para a Fase 5 se diferenciou.

\section{Análise de Dados}

Neste trabalho as respostas de interesse foram os encontros entre as peças promovidos pelas duplas e os efeitos que as mudanças sucessivas na definição do produto agregado poderiam produzir. Os produtos agregados (chamados na análise de dados de PA ou simplesmente acerto) foram todos os encontros entre as peças nos locais previamente determinados em cada fase das duas condições. Os encontros não reforçados (erros) foram chamados apenas de tentativas. Outras medidas registradas para a análise de dados foram a distância mínima em quadrantes que as peças separadamente e em dupla deveriam percorrer para a ocorrência do PA, a soma e a diferença do número de quadrantes a serem percorridos pelas peças, e o grau de dificuldade de cada fase para a produção do PA.

Com base na quantidade mínima de quadrantes pelos quais os participantes tinham que passar para que ocorresse o encontro especificado para cada fase, foi listada a diferença e a soma destes quadrantes. Decidiu-se por analisar a diferença e a soma entre 
os quadrantes percorridos, a fim de averiguar possíveis padrões nos resultados de acordo com a fase, ou seja, as duas operações foram realizadas para verificar se tanto a soma quanto a diferença entre a quantidade mínima de quadrantes a serem percorridos pelas peças demonstrariam dados válidos, sem que uma operação contradissesse a outra.

A distância em quadrantes foi contabilizada a partir do menor caminho possível para o encontro tanto para as peças individualmente quanto para a dupla. A distância mínima em quadrantes que as duplas deveriam passar foi subdividida em duas categorias: alternativas de rota que envolviam o total de quadrantes diferentes e alternativas em que necessariamente deveria haver repetição de quadrantes para que o encontro fosse possível. Para o cálculo do total de quadrantes diferentes, os quadrantes iniciais, os quadrantes onde os encontros ocorreram e os quadrantes em que uma ou as duas peças passariam mais de uma vez não foram considerados. Já para o número de repetições de quadrantes, foi contabilizada somente a quantidade de repetições imprescindíveis para o encontro, ou seja, repetições em que sem elas o encontro não seria possível de acordo com o menor caminho possível. Por exemplo, para um encontro ocorrer uma peça deveria passar pelo Quadrante 7, depois pelo Quadrante 8 e novamente pelo Quadrante 7, ou este encontro não aconteceria.

Em cada uma das fases e condições foi contabilizado o número de tentativas emitidas pelas duplas até a mudança de fase (critério de estabilidade). Para observar o desempenho em número de tentativas por condição, foram gerados gráficos com as curvas de aprendizagem contendo os totais de tentativas até o alcance do critério de estabilidade. Esperava-se que com a exposição contínua ao experimento, as duplas apresentassem curvas de aprendizagem decrescentes, por efeito do que se convencionou como "aprender a aprender" (learning set; Catania, 1999; Harlow, 1949). O fenômeno descrito por Harlow, em 1949, chamado "learning set” sugere que, a partir de exposições sucessivas a uma condição problema, a resolução seja mais rápida a cada tentativa. Ou seja, quanto 
mais vezes o sujeito é exposto a determinado tipo de problema, em menos tentativas a aquisição do repertório de solução do problema ocorrerá, devido à exposição anterior a contingências de problemas semelhantes. De acordo com os resultados descritos por Harlow (1949), no decorrer das fases do presente experimento, o número de tentativas até a mudança de fase deveria diminuir progressivamente para cada dupla. Além do número de tentativas por dupla, foi calculado o número médio de tentativas ocorridas no total de cada fase, incluindo todas as duplas, em cada condição e nas duas condições juntas (nomeada de média geral). $\mathrm{O}$ valor médio das tentativas foi calculado para as fases e separados em Condição 1 e Condição 2. O valor médio de tentativas foi gerado a partir do total de tentativas das duplas nas cinco fases de cada uma das condições. Já o valor médio geral foi obtido a partir dos valores médios das duas condições.

As fases foram ordenadas por grau de dificuldade, estabelecido a partir do valor médio de tentativas ocorridas, soma e diferença em distância de quadrantes necessários para o encontro das peças, número de quadrantes percorridos no total pelas duplas (desconsiderando repetições), e número de repetições de quadrantes necessários para a produção do PA. Dessa forma, seriam consideradas mais difíceis as fases com os maiores escores de tentativas ocorridas, maiores valores para soma e diferença os quadrantes que necessariamente deveriam ser percorridos pelas peças, maior quantidade de quadrantes percorridos no total até o encontro pelas duplas e número de repetições de quadrantes no trajeto para o encontro. Os gráficos contendo as fases classificadas por grau de dificuldade foram estabelecidos ordenando as fases da mais difícil para a mais fácil.

No presente trabalho a Condição 1 e a Condição 2 se diferenciaram apenas durante a Fase 5, onde o quadrante definido para o PA foi modificado. Por esse motivo, os dados referentes à distância das fases 1, 2, 3 e 4, tanto da Condição 1 quanto da Condição 2, foram analisados e apresentados em conjunto e os dados da Fase 5 foram separados em Condição 1 (Cond. 1) e Condição 2 (Cond. 2). 
Estão descritos na Tabela 1 os dados referentes à distância mínimas em quadrantes que cada uma das peças deveria percorrer, a soma e a diferença entre elas e os dados da distância mínima necessária para as duplas produzirem o PA. Portanto, de acordo com a menor distância possível, a peça amarela deveria passar por pelo menos dois quadrantes nas fases 1 e 2 (Cond. 1 e Cond. 2), por três nas fases 3, 4 e 5 (Cond. 2) e por quatro na Fase 5 (Cond. 1). Já a peça vermelha deveria se movimentar, nas duas condições, por dois quadrantes nas fases 1,2 e 3 e três quadrantes nas fases 4 e 5 das duas condições. $O$ somatório da distância por fase, a ser percorrida pelas duas peças foram quatro quadrantes na Fase 1 e na Fase 2, cinco quadrantes na Fase 3, seis quadrantes nas fases 4 e 5 (Cond. 2) e sete quadrantes na Fase 5 (Cond. 2). Quanto à diferença, os totais foram zero para as fases 1,2 , 4 e 5 (Cond. 2) e um para as fases 3 e 5 (Cond. 1).

Quanto aos dados das duplas, considerando cada quadrante apenas uma vez, obtiveram-se as seguintes distâncias mínimas em quadrantes: três quadrantes para as Fases 1 e 2, quatro quadrantes na Fase 3, cinco quadrantes para as fases 4 e 5 (Cond. 2) e seis quadrantes para a Fase 5 (Cond. 1). Dentre todas as fases, a Fase 5 da primeira condição foi a única em que era preciso que as duplas repetissem a passagem por pelo menos um quadrante para que houvesse a produção do PA. Nas outras fases foi possível o encontro sem que as peças transitassem por locais repetidos.

Tabela 1.

Distância Mínima em Quadrantes para a Produção do PA para as peças e para as duplas.

\begin{tabular}{lllllll}
\hline & \multicolumn{2}{l}{$\begin{array}{l}\text { Número de Quadrantes a serem percorridos } \\
\text { (Peças individuais) }\end{array}$} & $\begin{array}{l}\text { Número de Quadrantes a } \\
\text { serem percorridos (Duplas) }\end{array}$ \\
\cline { 2 - 5 } & Amarela & Vermelha & $\begin{array}{l}\text { Soma } \\
\text { entre } \\
\text { peças }\end{array}$ & $\begin{array}{l}\text { Diferença } \\
\text { entre peças }\end{array}$ & $\begin{array}{l}\text { Total para a Repetições } \\
\text { dupla }\end{array}$ & $\begin{array}{l}\text { Rara dupla } \\
\text { para }\end{array}$ \\
\hline Fase 1 & 2 & 2 & 4 & 0 & 3 & 0 \\
Fase 2 & 2 & 2 & 4 & 0 & 3 & 0
\end{tabular}




\begin{tabular}{lllllll} 
Fase 3 & 3 & 2 & 5 & 1 & 4 & 0 \\
Fase 4 & 3 & 3 & 6 & 0 & 5 & 0 \\
$\begin{array}{l}\text { Fase 5 } \\
\text { (Cond. 1) }\end{array}$ & 4 & 3 & 7 & 1 & 6 & 1 \\
$\begin{array}{l}\text { Fase 5 } \\
\text { (Cond. 2) }\end{array}$ & 3 & 3 & 6 & 0 & 5 & 0 \\
\hline
\end{tabular}

Nota. Os dados referentes às quantidades de quadrantes necessários para a produção do PA foram separados em peças e duplas. Nos valores para as peças estão os totais de quadrantes em que cada peça deveria passar, além da soma e da diferença entre o número de quadrantes mínimos para cada uma. Nos totais referentes às duplas, os dados foram separados em valores totais para as duplas, descartando repetições de quadrantes e valores contabilizando apenas quadrantes que se repetiram, desde que essa repetição fosse essencial para a formação do PA. Todas as distâncias foram calculadas a partir do menor caminho possível para o encontro. Apenas a Fase 5 foi tabulada em separado para as duas condições, por ser a única fase em que as condições se diferenciaram.

Em suma, foram contemplados na análise de dados o número de tentativas ocorridas para a mudança de fases e a distância em quadrantes percorrida pelas peças e pelas duplas.

\section{Resultados}

A Tabela 2 mostra que os maiores números médios de tentativas ocorreram na Fase 5, tanto para as condições 1 e 2, quanto para o índice geral. Já o menor valor médio em tentativas foi obtido no índice geral da Fase 2.

Tabela 2.

Número Médio de Tentativas por Fase.

\begin{tabular}{lccccc}
\hline & Fase 1 & Fase 2 & Fase 3 & Fase 4 & Fase 5 \\
\hline Condição 1 & 57,14 & 18,57 & 49 & 21,71 & 77,14 \\
Condição 2 & 42,33 & 17 & 10,66 & 36,66 & 47 \\
Geral & 49,73 & 17,78 & 29,83 & 29,18 & 62,07 \\
\hline
\end{tabular}

Nota. O valor médio de tentativas das fases foi calculado de acordo com o número de tentativas das duplas em cada fase, enquanto o valor geral foi obtido a partir dos valores das médias de cada uma das condições. 
De acordo com a Tabela 3, na primeira fase da Condição 1, para o alcance do critério de estabilidade, o maior número de tentativas foi realizado pela Dupla 4 e o menor número de tentativas, pela Dupla 1. Na segunda fase da mesma condição, os maiores e menores números de tentativas foram apresentados pelas duplas 2 e 4 , respectivamente. Já na fase 3, os maiores e menores valores em números de tentativas foram apresentados pelas duplas 4 e 1, nesta ordem. Ainda na Condição 1, durante a Fase 4, a dupla 6 apresentou o maior número de tentativas e a dupla 1, o menor. Por último, na Condição 1, a Dupla 5 exibiu o maior número de tentativas e a Dupla 4, o menor número de tentativas para a Fase 5. Durante a Condição 2, na Fase 1 a Dupla 10 apresentou o maior número de tentativas enquanto a Dupla 9, o menor. Na Fase 2, ao contrário, o maior valor em número de tentativas foi exibido pela Dupla 9 e o menor valor pela Dupla 10. A Dupla 10 apresentou o maior número de tentativas na Fase 3, enquanto a Dupla 9, o menor. Na Fase 4, o maior número de tentativas foi demonstrado pela Dupla 10 e o menor pela Dupla 9. Por fim, na Fase 5, a Dupla 10 também exibiu o maior escore em número de tentativas e a Dupla 8, o menor número de tentativas.

Tabela 3.

Tentativas Emitidas Pelas Duplas nas Condições 1 e 2.

\begin{tabular}{llllllll}
\hline & Dupla & Fase 1 & Fase 2 & Fase 3 & Fase 4 & Fase 5 \\
\hline & 1 & 18 & 11 & 5 & 5 & 6 \\
& 2 & 55 & 42 & 34 & 15 & 24 \\
Condição 1 & 3 & 22 & 14 & 41 & 12 & 155 \\
& 4 & 203 & 9 & 171 & 8 & 5 \\
& 5 & 25 & 18 & 47 & 28 & 159 \\
& & 49 & 20 & 36 & 69 & 110
\end{tabular}




\begin{tabular}{lcccccc} 
& 7 & 28 & 16 & 9 & 15 & 81 \\
\hline \multirow{2}{*}{ Condição 2 } & 8 & 50 & 13 & 11 & 16 & 9 \\
& 9 & 26 & 28 & 7 & 10 & 55 \\
& 10 & 51 & 10 & 14 & 84 & 77 \\
\hline
\end{tabular}

Com base nos dados obtidos as fases foram classificadas em graus de dificuldade a partir do número médio de tentativas até a mudança de fase, distância mínima total em quadrantes a serem percorridos pelas duplas, repetições necessárias para o encontro, e soma e diferença entre os quadrantes a serem percorridos pelas peças que foram necessários para a formação do PA. Os dados referentes ao grau de dificuldade de acordo com cada um dos critérios anteriormente mencionados estão apresentados nas Figuras 9 e 10. Note que as fases estão ordenadas em ordem decrescente com base no grau de dificuldade de cada uma, o que significa que as fases consideradas mais difíceis estão apresentadas primeiramente nas figuras.

Tendo em vista os dados apresentados nas Figuras 9 e 1011 e 12, verificou-se que tanto na Condição 1, quanto na Condição 2, a Fase 5 e a Fase 1 exibiram os maiores índices médios de tentativas, seguidas pelas fases 3, 4 e 2, na Condição 1 , e fases 4,2 e 3, na Condição 2. Quanto ao número total de quadrantes a serem percorridos minimamente pelas duplas na Condição 1, os maiores números de quadrantes foram nas fases 5 e 4, seguidas pelas fases 3, 1 e 2, respectivamente. Na Condição 2, os maiores índices em números de quadrantes foram nas fases 4 e 5, ambas com valor igual a 5, em seguida as fases 3, 1 e 2, nesta ordem (Fig. 12 e Fig. 13). De acordo com o critério de soma dos quadrantes a serem percorridos pelas peças na Condição 1, as fases que revelaram os maiores valores foram as fases 5 e 1 , seguidas pelas fases 4,1 e 2 , nesta ordem. Na Condição 2 os maiores valores foram apresentados pelas fases 5 e 4, em seguida vieram as fases 3, 1 e 2. Quanto ao critério de diferença entre os quadrantes a 
serem percorridos pelas peças na Condição 1, apenas as fase 1 e 3 apresentaram valores diferentes de 0 , sendo estes iguais a 1 . Por fim, na Condição 2 a única fase que apresentou valor diferente de 0 , também igual a 1, foi a Fase 3.

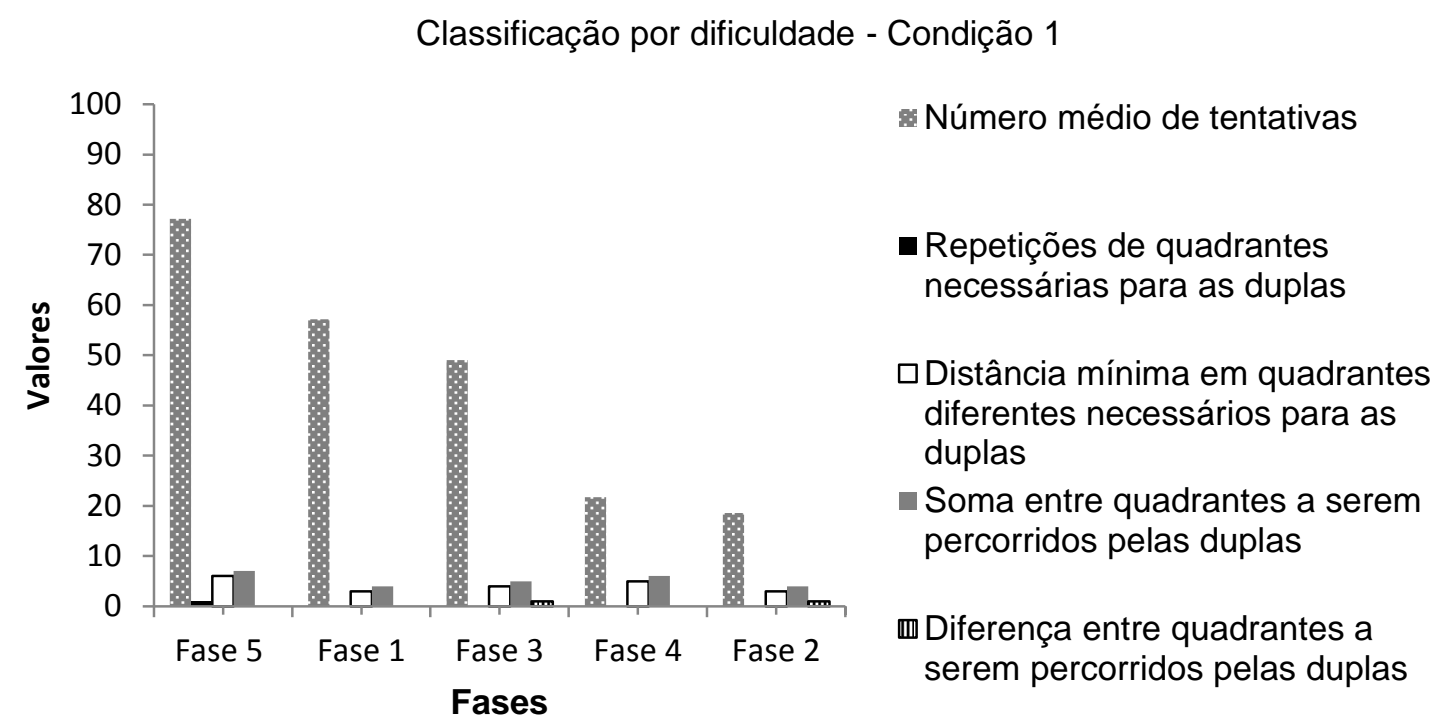

Figura 9. Fases da Condição 1 ordenadas em grau de dificuldade em ordem decrescente (da fase mais difícil para a fase mais fácil) a partir do número médio de tentativas, repetições de quadrantes pelas duplas, distância mínima em quadrantes para as duplas, soma e diferença da distância mínima necessária para as peças. A soma e a diferença indicadas referem-se entre os a distância percorrida pelas peças em quadrantes.

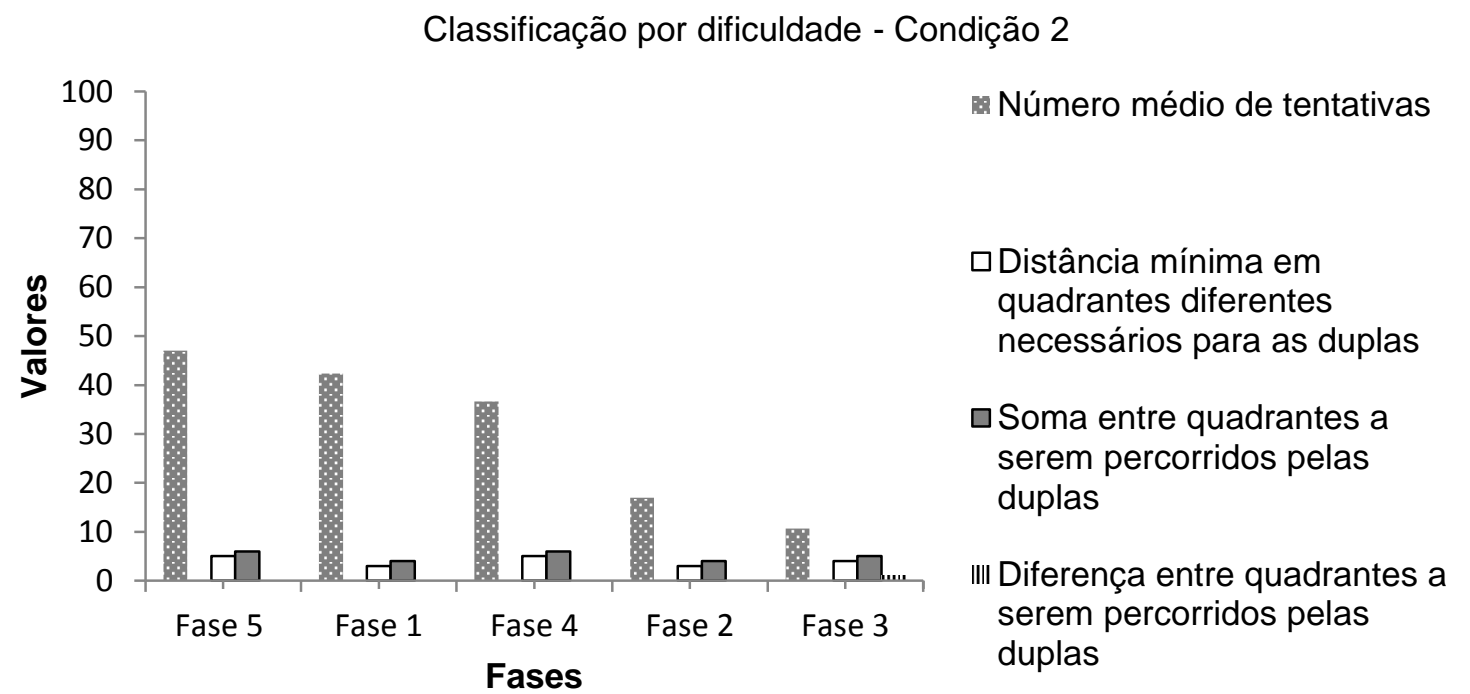

Figura 10. Fases da Condição 2 ordenadas em grau de dificuldade em ordem decrescente (da fase mais difícil para a fase mais fácil) a partir do número médio de tentativas, repetições de quadrantes pelas duplas, distância mínima em quadrantes para as duplas, soma e diferença da distância mínima necessária para as peças. A soma e a diferença referem-se entre os a distância percorrida pelas peças em quadrantes. 
As Figuras 11 e 12 mostram as curvas de aprendizagem das duplas em cada uma das condições. Segundo essas figuras, houve ascendência na curva de aprendizagem das duplas 3, 5, 6, 7, 9 e 10 mostrando que as duplas aumentaram o número de tentativas necessárias para a mudança de fase, no decorrer do experimento. As curvas das duplas 1, 2, 4 e 8 sugerem diminuição do número de tentativas necessárias para a mudança de fase, embora a curva da dupla 4 evidencie aumento pontual do número de tentativas na fase 3 .

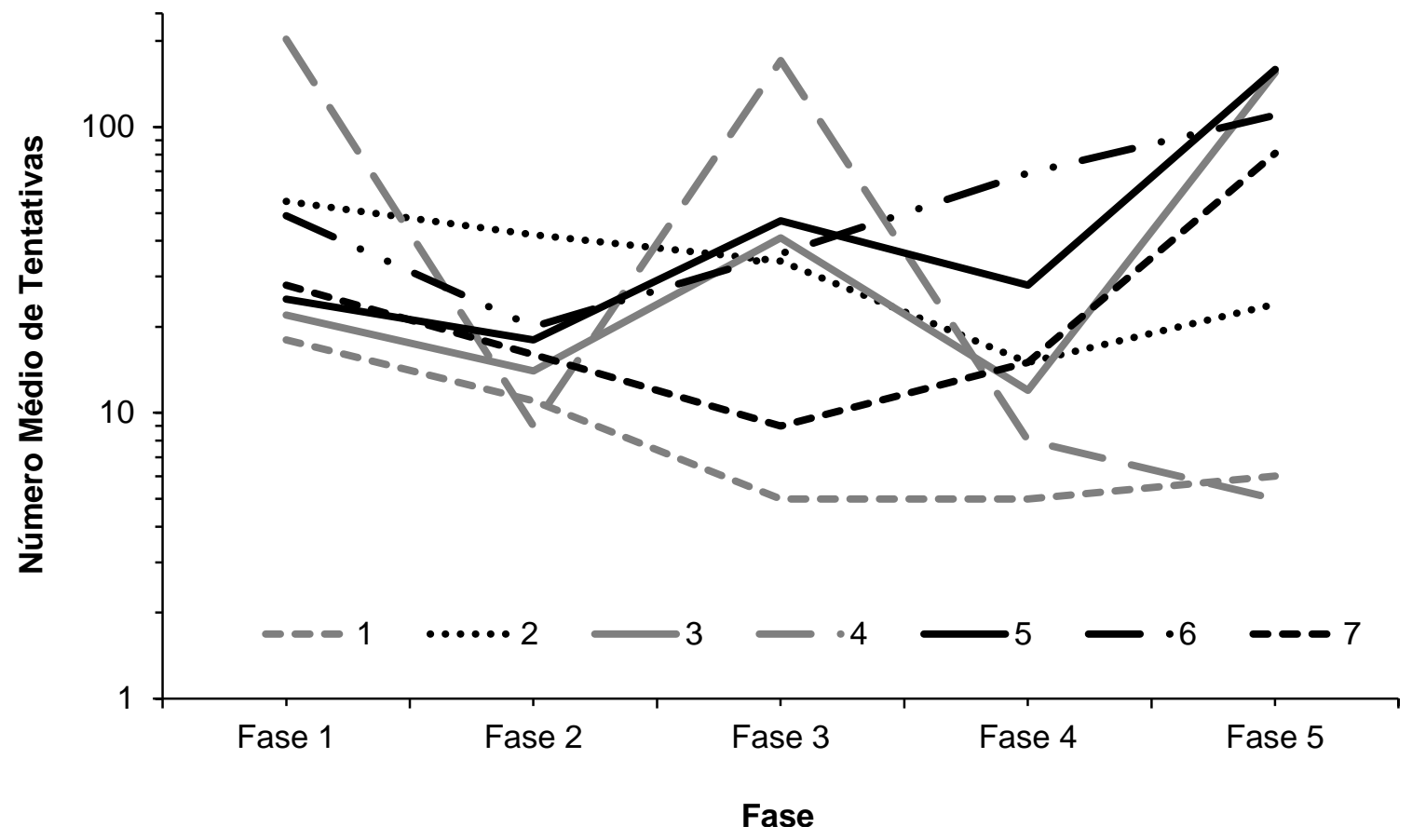

Figura 11. Curva de aprendizagem das duplas durante a Condição 1 em relação ao número de tentativas para a mudança de fase representado em logaritmos. No gráfico estão apresentados os valores totais das tentativas das duplas 1, 2, 3, 4, 5, 6 e 7 nas cinco fases da primeira condição. Em relação aos valores da primeira fase e da última, apenas as duplas 1, 2 e 4 têm queda nos valores, as outras duplas obtiveram valores crescentes no decorrer das fases. 


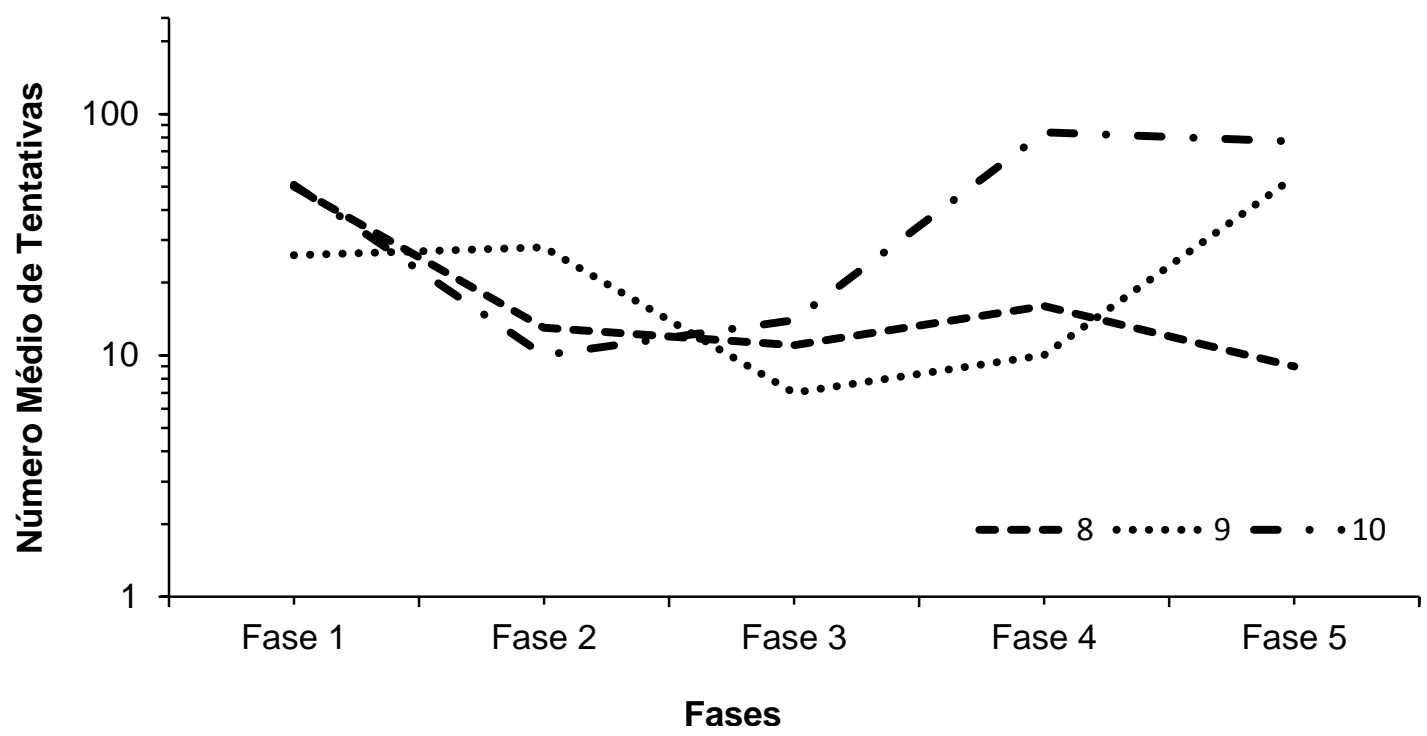

Figura 12. Curva de aprendizagem das duplas durante a Condição 2 em relação ao número de tentativas para a mudança de fase. No gráfico estão apresentados os valores das tentativas das duplas 7, 8 e 9 nas cinco fases da segunda condição. Em relação aos valores da primeira fase e da última, apenas a dupla 8 tem valor decrescente, as demais tiveram aumento no número de tentativas ao final da condição.

Como visto nos dados apresentados pelas Figuras 11 e 12, para três duplas (1, 2 e 4) das sete participantes da Condição 1 e uma dupla (8) das três participantes da Condição 2, as mudanças sucessivas na definição do produto agregado produziram queda no total de tentativas para a mudança de fase. Contudo, para as outras seis duplas, quatro $(3,5,6$ e 7) que participaram da primeira condição e duas (9 e 10) da segunda condição, após as mudanças sucessivas nas condições para a produção do PA, houve aumento no número de tentativas até o alcance do critério de estabilidade. De acordo com a variabilidade dos dados apresentados, não foi possível afirmar efeitos sistemáticos na aprendizagem das duplas a partir das mudanças sucessivas nas condições.

\section{Discussão}

O presente trabalho investigou os efeitos sobre os padrões de aprendizagem de comportamentos que levavam ao encontro de peças (produto agregado) em um tabuleiro 
em função de mudanças sucessivas na definição do local onde as peças deveriam se encontrar, em um procedimento arranjando uma metacontingência.

Em geral, as Fases 1 e 5 das duas condições foram as fases com o maior número médio de tentativas, sendo que a Fase 5 da primeira condição foi a fase com o maior número de tentativas de todo o experimento. Uma possível explicação para o alto número de tentativas necessário para completar a Fase 1 pode ser a ingenuidade experimental dos participantes. Por ser esta a primeira fase, ainda não havia sido estabelecido nenhum contato com a condição experimental; portanto, faz sentido a aprendizagem ter ocorrido de forma mais lenta. Com base nessa possibilidade (maior dificuldade para a aquisição do PA na Fase 1) e para promover as ocorrências iniciais do PA, o local do encontro foi estabelecido em um quadrante central (Q7) do tabuleiro. Por outro lado, a quinta fase também obteve valores altos em números de tentativas. Critérios posteriormente estabelecidos para avaliar o grau de dificuldade de cada fase foram usados como uma possível explicação para o aumento no número de tentativas das duplas (i.e. número médio de tentativas e número de quadrantes exigidos para o menor caminho que possibilitasse o encontro). Para todos os critérios, a Fase 5 das duas condições foi considerada a fase mais difícil, apresentando os maiores escores (até mesmo do que a primeira fase), apesar de na condição 2, a Fase 4 ter apresentado o mesmo valor de quadrantes diferentes exigidos para o encontro. A Condição 2 foi inserida, inclusive sob controle dos dados apresentados na Condição 1, referentes ao número de tentativas reveladas pelas duplas, tendo em vista o aumento para a maioria das duplas.

Comparando-se as Fases 1 e 5 de todo o experimento, as duplas 1, 2, 4 e 8 apresentaram resultados consistentes com os de Harlow (1949) no que se refere ao fenômeno chamado de learning set, revelando queda no número de tentativas para a mudança de fase, logo queda também nas curvas de aprendizagem. As outras duplas apresentaram resultados divergentes, com acréscimo no número de tentativas ao longo 
das fases. Tendo em vista os critérios de dificuldade posteriormente estabelecidos, nas duas condições, percebeu-se que o grau de dificuldade aumentou no decorrer das fases, a partir da terceira fase. Contudo, observando os resultados das Fases 1 e 2, onde o grau de dificuldade era semelhante, para todas as duplas (com exceção da Dupla 9) houve decréscimo do número de tentativas até a mudança de fase, o que pode ser uma evidência de learning set.

É possível explicar a ascendência na curva de aprendizagem durante a Fase 5 das duas condições também pelo número de quadrantes exigidos minimamente para a produção do PA e a quantidade de repetições de quadrantes para a mesma tarefa. Nas fases consecutivas em que o número mínimo de quadrantes necessários para o encontro foi igual a 3 (Fases 1 e 2), as curvas de aprendizagem das duplas decresceram (com exceção da Dupla 9). Nas fases consecutivas em que as curvas de aprendizagem não decresceram consistentemente, o número mínimo de quadrantes a serem percorridos eram 4, 5, e 6 (Fases 3, 4, e 5), na Condição 1 e 4 e 5, na Condição 2. Na Fase 5 da primeira condição, além do maior número de quadrantes exigidos (6), foi a única fase em que era necessário que uma das peças passasse por pelo menos um quadrante por duas vezes.

Três do total de duplas participantes (1, 3 e 5) apresentaram um pico na curva de aprendizagem durante a Fase 3. Na Fase 3, assim como na Fase 5, a diferença entre os quadrantes que deveriam ser percorridos pelas peças de cada dupla era igual a 1; para as outras fases, essa diferença foi igual a zero. Um ponto importante a ser observado é que na Fase 3 os valores de soma de quadrantes a serem percorridos pelas peças separadamente, o número de quadrantes percorridos por dupla e quadrantes diferentes exigidos, são maiores que os demonstrados nas fases 1 e 2. Apesar da Fase 4 apresentar valores ainda mais altos que a Fase 3 no que concerne à soma anteriormente citada, apenas a Fase 3 juntamente com a Fase 5 da primeira condição obtiveram o valor de diferença entre os quadrantes das peças igual a 1. 
O aumento do número de tentativas de algumas duplas pode ter ocorrido, entre outros fatores, em decorrência de como as peças deveriam se movimentar no tabuleiro para produzir o PA. O jogo sempre começava com a peça amarela localizada na parte superior do tabuleiro e as peças saiam sempre da mesma localização (peça amarela do Q1 e peça vermelha do Q16). As Fases 3 e 5 (da Condição 1) eram as únicas em que a localização do encontro esperado (PA) fugia do centro do tabuleiro (o centro estava localizado entre os quadrantes 6, 7, 10 e 11). Na Fase 5 da primeira condição, era necessário que uma das peças repetisse a passagem por algum quadrante, o que seria equivalente a ir e voltar para que a outra peça pudesse chegar para o encontro. Porém, mesmo quando a localização do PA mudou para o Quadrante 11, na Fase 5 da Condição 2, o número médio de tentativas continuou crescente ou simplesmente não diminuiu, comparando-se as fases entre si.

Com base nos dados obtidos no presente experimento, parece possível argumentar que durante as fases em que as peças deveriam fazer movimentos mais elaborados (i.e., passar por mais quadrantes, passar mais de uma vez pelo mesmo quadrante, ou ter que “dar voltas" para esperar o colega se aproximar para o encontro), o número de tentativas necessárias para o critério de aprendizagem foi maior. No entanto, experimentos adicionais são necessários para isolar estas variáveis, estabelecendo-se quais delas, de fato, exercem influência sobre o a aprendizagem repetida em uma metacontingência.

De qualquer forma, assim como foi sugerido por Todorov (1983) para estudos sobre estados de transição, e de forma consistente com os resultados obtidos por Boren e Devine (1968), Boren (1969), Thompson (1971, 1973, 1974, 1975, 1980), Harting e McMillan (1976), Schrot, Boren e Moerschbaecher (1976), Hursh (1977), Moerschbaecher, Boren, Schrot e Fontes (1978), Thompson \& Moerschbaecher (1980, 1981), Thompson, Moerschbaecher e Winsauer (1983), Vaughan (1985), Peele e Baron (1988), Bickel e Griffiths (1989), Higgins e Henningfield (1989), Snodgrass e McMillan 
(1989), Bickel, Higgins e Hughes (1991), Kelly, Fischman, Foltin e Brady (1991), Vasconcelos (1999), Gimenez e Vasconcelos (1999), Dermer e Dermer (2000), o presente trabalho é uma confirmação de que, por meio do procedimento de aquisição repetida, é possível trabalhar com linhas de base comparáveis (i.e., intrassujeitos) para o comportamento de duas pessoas que se comportam de maneira entrelaçada. Dessa forma, este tipo de metodologia se torna viável para o estudo, também, de comportamentos emitidos culturalmente.

Adicionalmente, o procedimento de aquisição repetida pode ser uma alternativa para minimizar a quantidade de participantes necessários em pesquisas com humanos, facilitando estudos sobre o comportamento emitido no contexto cultural. Como demonstrado por pesquisas anteriores, procedimentos longos e extremamente complexos muitas vezes têm alto índice de desistência por parte dos participantes e/ou requerem um treino prévio para a tarefa principal o que, por sua vez, pode levar a experimentos longos e com alto índice de mortalidade. Nesse sentido, o presente experimento se une aos de Vasconcelos (2014) e Azevedo (2015), demonstrando que é possível utilizar procedimentos simples, sem a necessidade de modelagem prévia para a tarefa e sem o uso de reforçadores arbitrários para os comportamentos emitidos individualmente, para o estudo experimental de metacontingências.

Com o uso do procedimento de aquisição repetida no estudo de metacontingências e a possibilidade de estudar linhas de base comparáveis mesmo após o contato com as condições experimentais, é possível otimizar o tempo consumido nos experimentos e o número de participantes utilizados. Diminuindo o custo em termos de tempo gasto ou de dificuldades de alocação de recursos para o experimento, é possível atrair mais analistas do comportamento para o estudo dos princípios envolvidos no terceiro nível de seleção. Um maior número de estudos na área, por sua vez, deve auxiliar na busca de consenso em termos teóricos e experimentais sobre práticas culturais. Outra vantagem da utilização 
do procedimento aqui descrito é a possibilidade do estudo de propriedades comuns ao comportamento operante (e.g. discriminação de estímulos, generalização, esquemas de reforçamento, sensibilidade a diferentes tipos de consequências, reforçamento arbitrário vs. reforçamento natural e controle aversivo) na análise do comportamento emitido em sociedade, devido sua possibilidade de comparação entre várias linhas de base. Tais linhas de base disponíveis para comparação facilitam a manipulação da variável independente em questão, uma vez que é possível, por exemplo, em uma mesma sessão manipular mais de uma variável, já que em cada condição ocorre uma nova aprendizagem.

Por se tratar de um estudo pioneiro na área, outras possíveis variáveis além das aqui identificadas e discutidas podem ter tido influência sobre os resultados. Entretanto, ainda assim, o objetivo de verificar os efeitos produzidos pelas mudanças sucessivas no local do PA foi atingido. É extremamente importante a realização de outros estudos que possam resolver questões empíricas e sistematizar alguns dados a fim de dissipar problemas de ordem conceitual e prática. Em experimentos futuros abordando o tema e o procedimento de aquisição repetida, seria interessante programar os encontros a serem reforçados para ocorrerem de maneira aleatória para que se possa minimizar o viés da escolha dos quadrantes por parte do experimentador, bem como a saída das peças de lugares também aleatórios, de modo a igualar os quadrantes em termos de dificuldade segundo sua localização. Além disso, seria conveniente em termos experimentais, utilizar o tabuleiro em uma configuração de quadrantes com uma área maior para cada um deles. A necessidade de um espaço diferente ao utilizado se deve ao fato de que, mesmo quando os participantes? passavam a responder de maneira adequada, se locomovendo a fim de se encontrar no mesmo local, caso a dupla não ficasse com as duas peças no quadrante esperado, ocorria um encontro errado, aumentando o número de tentativas a serem emitidas em, no mínimo, mais cinco, uma vez que este foi o critério estabelecido para se mudar de fases (cinco acertos consecutivos). Semelhante ao "click" que a barra faz ao 
ser pressionada pelo rato, o quadrante onde o PA foi produzido poderia ficar destacado por 1 ou 2 segundos para que ficasse clara a condição de reforçamento aos participantes. Outro aspecto interessante para pesquisas futuras seria, após a realização do experimento, solicitar que os participantes escrevessem ou dissessem ao pesquisador qual foi o critério estabelecido como estratégia para ganhar o jogo, para se verificar qual o possível controle pelas contingências ou quais as regras (supersticiosas ou não) podem ter surgido durante o experimento.

Com base na revisão realizada, Sousa e Carrara (2013) discutem que é evidente a "lacuna teórico-prática" (p. 93) a ser preenchida por trabalhos experimentais sobre metacontingência. Assim como outros autores anteriormente citados, estes também defendem a necessidade de estudos empíricos na área de práticas culturais, para se estabelecerem princípios gerais, assim como na análise do comportamento individual. De acordo com o exposto aqui é possível afirmar o lugar do analista do comportamento na análise e planejamento de práticas culturais, além do comportamento dos indivíduos no cenário cultural. 


\section{Referências}

Andery, M. A. P. A., Micheletto, N., \& Sério, T. M. A. P. (2005). A análise de fenômenos sociais: esboçando uma proposta para a identificação de contingências entrelaçadas e metacontingências. Em Todorov, J. C., Martone, R. C. \& Moreira, M. B. (orgs). Metacontingências: comportamento, cultura e sociedade. Santo André, SP: ESETec. Andery, M.A.P., \& Sério, T.M.A.P. (2005). O conceito de metacontingências: afinal, a velha contingência de reforçamento é insuficiente? Em Todorov, J.C.; Martone, R.C.; Moreira, M.B. (2005). Metacontingências: comportamento, cultura e sociedade. Santo André: Esetec. (trabalho original publicado em 1997).

Azevedo, R. M. F. (2015). Controle discriminativo em metacontingência. Dissertação de mestrado. Universidade de Brasília, Brasília, DF, Brasil.

Bickel, W. K., Higgins, S. T., \& Griffiths, R. R. (1989). Repeated diazepam administration: Effects on the acquisition and performance of response chains in humans. Journal of the experimental analysis of behavior, 52(1), 47-56.

Bickel, W. K., Higgins, S. T., \& Hughes, J. R. (1991). The effects of diazepam and triazolam on repeated acquisition and performance of response sequences with an observing response. Journal of the experimental analysis of behavior, 56(2), 217237.

Boren, J. (1963). Repeated acquisition of new behavioral chains. American Psychologist, 17, 421.

Boren, J. (1969). Some variables affecting the superstitious chaining of responses. Journal of the Experimental Analysis of Behavior, 12(6), 959-969.

Boren, J. J., \& Devine, D. D. (1968). The repeated acquisition of behavioral chains. Journal of the Experimental Analysis of Behavior, 11(6), 651-660. 
Catania, C.A. (1999). Aprendizagem: comportamento, linguagem e cognição. Trad. Deisy das Graça de Souza. Porto Alegre: Artmed.

Dermer, N. S., \& Dermer, M. L. (2000). Chains: a Quickbasic 4.5 program for studying variables affecting human learning. Experimental Analysis of Human Behavior Bulletin, 18, 23-27.

Gimenes, L. da S., \& Vasconcelos, L. A. (1999). Efeitos da radiação ionizante sobre comportamentos mantidos por contingências operantes. Psicologia: Teoria $e$ Pesquisa, 15(3), 219-225.

Glenn, S. S. (1986). Metacontingencies in walden two. Behavior Analysis and Social Action, 5, 2-8.

Glenn, S. S. (1988). Contingencies and metacontingencies: Toward a synthesis of behavior analysis and cultural materialism. The Behavior Analyst, 11(2), 161.

Glenn, S. S. (2004). Individual behavior, culture, and social change. The Behavior Analyst, 27(2), 133-151.

Hardin, G. (1968). The tragedy of the commons. science, 162(3859), 1243-1248.

Harlow, H. F. (1949). The formation of learning sets. Psychological review,56(1), 51-65.

Harting, J., \& McMillan, D. E. (1976). Repeated acquisition of responses by pigeons under chained and tandem schedules with reset and non-reset contingencies. The Psychological Record, 26, 361-367.

Higgins, S. T., Woodward, B. M., \& Henningfield, J. E. (1989). Effects of atropine on the repeated acquisition and performance of response sequences in humans. Journal of the experimental analysis of behavior, 51(1), 5-15.

Houmanfar, R., \& Rodrigues, N. J. (2006). The metacontingency and the behavior contingency: points of contact and departure. Behavior and Social Issues. 15(1), 1330. 
Houmanfar, R., Rodrigues, N., \& Ward, T. (2010). Emergence \& metacontingency: points of contact and departure. Behavior And Social Issues, 19, 53-78.

Hursh, S. R. (1977). The conditioned reinforcement of repeated acquisition. Journal of the Experimental Analysis of Behavior, 27(2), 315-326.

Kelly, T.H., Fischman, M. W., Foltin, R. W., \& Brady, J. V. (1991). Response patterns and cardiovascular effects during response sequence acquisition by humans. Journal of The Experimental Analysis of Behavior, 56(3), 557-574.

Malott, M., \& Glenn, S. S. (2006). Targets of intervention in cultural and behavioral change. Behavior and Social Issues, 15(1), 31-56.

Martone, R. C. (2008). Efeitos de consequências externas e de mudanças na constituição do grupo sobre a distribuição dos ganhos em uma metacontingência experimental. Tese de doutorado. Universidade de Brasília, Brasília, DF, Brasil.

Martone, R. C., \& Todorov, J. C. (2007). O desenvolvimento do conceito de metacontingência. Revista Brasileira de Análise do Comportamento, 3(2), 181-190.

Miccione, M. M. (2009). Variáveis de controle sobre o responder ordinal: revisitando estudos empíricos. Dissertação de mestrado. Universidade Federal do Pará, Pará, PA, Brasília.

Micheletto, N. (2001). Bases Filosóficas do Behaviorismo Radical. Em R. A. Banaco (org.). Sobre comportamento e cognição: aspectos teóricos, metodológicos e de formação em análise do comportamento e terapia cognitivista. Santo André, SP: ESETec. 29-44.

Moerschbaecher, J. M., Boren, J. J., \& Schrot, J. (1978). Repeated acquisition of conditional discriminations. Journal of the Experimental Analysis of Behavior, 29(2), 225- 232. 
Moerschbaecher, J. M., Boren, J. J., Schrot, J., \& Fontes, C. S. (1979). Effects of cocaine and $d$-amphetamine on the repeated acquisition and performance of conditional discriminations. Journal of the Experimental Analysis of Behavior, 31(1), 127-140.

Moerschbaecher, J. M., \& Thompson, D.M. (1980). Effects of $d$ - amphetamine, cocaine and phencyclidine on the acquisition of responses sequences with and without stimulus fading. Journal of The Experimental Analysis of Behavior, 33(3), 369-381.

Moreira, M. B., Martone, R. C., \& Todorov, J. C. (2005). Os fins justificam os meios de uma Ciência do Comportamento. Em J. C. Todorov, R. C. Martone e M. B. Moreira (Ed.), Metacontingências: comportamento, cultura e sociedade. Santo André:, SP: ESETec Editores Associados. 9-12.

Naves, A. R. C. X., \& Vasconcelos, L. A. (2008) O estudo da família: contingências e metacontingências. Revista Brasileira de Análise do Comportamento, 4(1), 13-25.

Peele, D. B., \& Baron, S. P. (1988). Effects of scopolamine on repeated acquisition of radial-arm maze performance by rats. Journal of the Experimental Analysis of Behavior, 49(2), 275-290.

Pereira, J.M.C. (2008). Investigação experimental de metacontingências: separação do produto agregado e da consequência individual. Dissertação de mestrado. Pontifícia Universidade Católica de São Paulo, São Paulo, SP, Brasil.

Sampaio, A. A. S., \& Andery, M. A. P. A. (2010). Comportamento social, produção agregada e prática cultural: uma análise comportamental de fenômenos sociais. Psicologia: Teoria e Pesquisa, 26(1), 183-192.

Santos, L.F (2010). Treino de autocontrole e aquisição repetida em crianças diagnosticadas de TDAH medicadas com Metilfenidato. Tese de Doutorado. Brasília: Universidade de Brasília. 
Schrot, J., Boren, J. J., \& Moerschbaecher, J. M. (1976). Sequential reacquisition as a function of timeout from avoidance. Journal of The Experimental Analysis of Behavior, 25(3), 303-310.

Sidman, M. (1960). Tactics of scientific research. New York: Basic Books.

Skinner, B. F. (1948). Walden Two. New York: Macmillan.

Skinner, B. F. (1968). The technology of teaching. New York: Appleton-Century Crofts.

Skinner, B. F.. (2007). Seleção por consequências. Revista Brasileira de Terapia Comportamental e Cognitiva, 9(1), 129-137. Trad. de C. R. X. Cançado, P. G. Soares e S. Cirino (Obra original publicada em 1981).

Skinner, B. F. (2003). Ciência e comportamento humano (11 ${ }^{\mathrm{a}} \mathrm{ed}$.). Trad. de J. C. Todorov e R. Azzi. São Paulo: Martins Fontes. (Obra original publicada em 1953).

Snodgrass, S. H., \& McMillan, D. E. (1989). Repeated acquisition of behavioral chains: responses sequences or conditional discriminations? Journal of the Experimental Analysis of Behavior, 51(2), 233-241.

Souza, V. B., \& Carrara, K. (2013). Delineamentos culturais: implicações da transferência de controle de reforçadores arbitrários e naturais e de imediatos a atrasados. Revista Brasileira de Terapia Comportamental e Cognitiva, 15(1), 83-98.

Thompson, D. M. (1971). Transition to a steady state of repeated acquisition. Psychonomic Science, 24(2), 236-238.

Thompson, D.M. (1973). Repeated aquisition as a behavioral baseline for studying drug effects. The Journal of Pharmacology and Experimental Terapeutics, 184(2), 506514.

Thompson, D. M. (1974). Repeated acquisition of behavioral chains under chronic drug conditions. The Journal of Pharmacology and Experimental Therapeutics, 188(3), 700-713. 
Thompson, D. M. (1975). Repeated acquisition of responses sequences: stimulus control and drugs. Journal of the Experimental Analysis of Behavior, 23(3), 429-436.

Thompson, D. M. (1980). Selective antagonism of the rate-decreasing effect of damphetamine chlorpromazine in a repeated-acquisition task. Journal of the Experimental Analysis of Behavior, 34(1), 87-92.

Thompson, D. M., \& Moerschbaecher, J. M. (1980). Effects of $d$-amphetamine and cocaine on strained ratio behavior in a repeated-acquisition task. Journal of the Experimental Analysis of Behavior, 33(1), 141-148.

Thompson, D. M., \& Moerschbaecher, J. M. (1981). Selective antagonism of the errorincreasing effect of morphine by naloxone in a repeated-acquisition task. Journal of the Experimental Analysis of Behavior, 36(3), 371-380.

Thompson, D. M., Moerschbaecher, J. M., \& Winsauer, P. J. (1983). Drug effect on repeated acquisition: comparison of cumulative and non-cumulative dosing. Journal of the Experimental Analysis of Behavior, 39(1), 175-184.

Todorov, J. C. (1983). Estados de transição e estados transitórios. Anais da XIII Reunião Anual de Psicologia, 13, 327-342.

Todorov, J. C. (1987). A constituição como metacontingência. Psicologia: Ciência e Profissão, 7(1), 9-13.

Todorov, J. C. (2007). A psicologia como estudos de interações. Psicologia: Teoria e Pesquisa, 23, 057-061.

Todorov, J. C. (2009). Behavioral analysis of non-experimental data associated with cultural practices. Behavior and Social Issues, 18(1), 10-14.

Todorov, J. C. (2010). Schedules of cultural selection: Comments on "Emergence and Metacontingency". Behavior and Social Issues, 19, 86-89.

Todorov, J. C. (2012). Metacontingências e a análise comportamental de práticas culturais. Clínica \& Cultura, 1(1), 36-45. 
Todorov, J. C. (2013). Conservation and transformation of cultural practices through contingencies and metaconitngencies. Behavior and Social Issues, 22, 64-73.

Todorov, J. C., \& Vianney, J. B. (2013). Xadrez (Versão 6.2) [Programa de computador]. Brasília, DF: Brasil.

Tucker, A. W. (1983). The Mathematics of Tucker: A Sampler. The Two-Year College Mathematics Journal, 14(3), 228-232.

Vasconcelos, L. A. (1999). Radiação ionizante: efeitos sobre a aquisição e o desempenho do comportamento operante. Tese de doutorado. Universidade de Brasília, Brasília, DF, Brasil.

Vasconcelos, I. G. (2014). Um procedimento experimental de modelagem de respostas para seleção do produto agregado em metacontingências. Dissertação de mestrado. Universidade de Brasília, Brasília, DF, Brasil.

Vaughan, M. E. (1985). Repeated acquisition in the analysis of rule-governed behavior. Journal of the Experimental Analysis of Behavior, 44(2), 175-184.

Velasco, S. M., Garcia-Mijares, M., \& Tomanari, G. Y. (2010). Fundamentos Metodológicos da Pesquisa em Análise Experimental do Comportamento. Psicologia em Pesquisa, UFJF, 4(2), 150-155.

Vichi, C. (2004). Igualdade ou desigualdade em pequeno grupo: um análogo experimental de manipulação de uma prática cultural. Dissertação de mestrado. Pontifícia Universidade Católica de São Paulo, São Paulo, SP, Brasil.

Vieira, M.C. (2010) Condições antecedentes participam de metacontingências? Dissertação de mestrado. São Paulo: Pontifícia Universidade Católica de São Paulo. 
ANEXOS 


\section{ANEXO 1}

\section{TERMO DE AUTORIZAÇÃO PARA COLETA DE DADOS}

Brasília, de de 2014

Prezado Sr.,

Estamos realizando o estudo do "Comportamento Em Situação de Jogo", coordenado pela estudante de mestrado em Ciências do Comportamento Fabiana Azevedo de Andrade, sob orientação do prof. Dr. João Cláudio Todorov (Universidade de Brasília - Instituto de Psicologia).

Solicitamos o seu consentimento para a realização da coleta de dados na instituição pela qual o senhor é responsável. A coleta se dará com alunos que se disponibilizarem voluntariamente. Assinando este termo, o senhor concorda e autoriza a coleta.

Este documento foi elaborado em duas vias, uma ficará com a pesquisadora responsável pela pesquisa e a outra com o (a) senhor(a).

Em caso de dúvidas, por favor, entre em contato com Fabiana Azevedo de Andrade fabi.azzevedo@gmail.com.

Atenciosamente,

Fabiana Azevedo de Andrade

João Cláudio Todorov

Assinatura do responsável pela instituição

Endereço: UNB-ICC Sul - Instituto de Psicologia. 


\section{ANEXO 2}

\section{TERMO DE CONSENTIMENTO LIVRE E ESCLARECIDO}

\begin{tabular}{l|l|}
\hline Nome: & Idade: \\
\hline Módulo: & Email: \\
\hline Já participou de pesquisas em psicologia anteriormente: ( ) sim ( ) não \\
Gostaria de receber informações posteriores sobre a pesquisa: ( r) sim ( ) não \\
Brasília,__ de_ de 201_.
\end{tabular}

Olá,

Estamos realizando o estudo do "Comportamento Em Situação de Jogo", coordenado pela estudante de mestrado em Ciências do Comportamento Fabiana Azevedo de Andrade, sob orientação do prof. Dr. João Cláudio Todorov (Universidade de Brasília - Instituto de Psicologia). Solicitamos o seu consentimento para participar voluntariamente desta pesquisa. Assinando este termo, você concorda em participar do estudo ciente de que o áudio da atividade poderá ser gravado e que os resultados do estudo poderão ser divulgados sem qualquer identificação dos participantes, preservando o sigilo das informações sobre seu desempenho pessoal. Mesmo após assinar este termo, você pode desistir de continuar com a realização da atividade a qualquer momento, sem qualquer ônus. As informações com relação à assinatura do TCLE ou os direitos do sujeito da pesquisa podem ser obtidos através do e-mail do CEP/IH cep_ih@unb.br.

Este documento foi elaborado em duas vias, uma ficará com a pesquisadora responsável pela pesquisa e a outra com você.

Em caso de dúvidas, por favor, entre em contato com Fabiana Azevedo de Andrade - fabi.azzevedo@ gmail.com.

Atenciosamente,

Fabiana Azevedo de Andrade

João Cláudio Todorov

Assinatura do Participante

Endereço: UNB-ICC Sul - Instituto de Psicologia 